\title{
Blocking MAPK/ERK pathway sensitizes hepatocellular carcinoma cells to temozolomide via downregulating MGMT expression
}

\author{
Qiang Li ${ }^{1,2 \#}$, Bingjie Ren ${ }^{1 \#}$, Qi Gui ${ }^{1,2 \#}$, Jing Zhao ${ }^{3}$, Mengyao Wu ${ }^{1}$, Meng Shen ${ }^{1}$, Dapeng Li $^{1}$, Daoming Li $^{1}$, \\ Kai Chen ${ }^{1}$, Min Tao ${ }^{1}$, Rongrui Liang ${ }^{1,4}$ \\ ${ }^{1}$ Department of Oncology, the First Affiliated Hospital of Soochow University, Suzhou, China; ${ }^{2}$ Department of Chemotherapy, Jiangxi Cancer \\ Hospital, Nanchang, China; ${ }^{3}$ Department of Radiation Oncology, the First Affiliated Hospital of Soochow University, Suzhou, China; ${ }^{4}$ Division of \\ Neurosurgery, City of Hope Beckman Research Institute, Duarte, CA, USA \\ Contributions: (I) Conception and design: R Liang, M Tao, K Chen; (II) Administrative support: R Liang, M Tao, K Chen; (III) Provision of \\ study materials or patients: Q Li, B Ren, Q Gui, D Li, D Li; (IV) Collection and assembly of data: Q Li, B Ren, Q Gui; (V) Data analysis and \\ interpretation: B Ren, J Zhao, M Wu, M Shen; (VI) Manuscript writing: All authors; (VII) Final approval of manuscript: All authors. \\ \#These authors contributed equally to this work. \\ Correspondence to: Rongrui Liang; Min Tao. Department of Oncology, the First Affiliated Hospital of Soochow University, Suzhou, China. \\ Email: lengbeng@suda.edu.cn; taomin@suda.edu.cn.
}

Background: Hepatocellular carcinoma (HCC) is the fourth most common malignant tumor in China. Temozolomide (TMZ) is a common chemotherapy drug which can effectively kill HCC cells in vitro. However, it is possible that HCC cells possess intrinsic resistance to TMZ. A key mechanism of TMZ resistance is the overexpression of O6-methylguanine-DNA methyltransferase (MGMT). Studies have shown that MAPK may be related to MGMT expression, U0126 is a highly selective inhibitor of MEK1 and MEK2, which were crucial molecule in cascade of mitogen-activated protein kinase/extracellular signal regulated kinase (MAPK/ERK) pathway. Sorafenib was another widely applicated target drug in HCC which could inhibit multiple kinases including MAPK/ERK. This research was aimed to investigate the efficacy of MAPK/ERK inhibitor U0126 and sorafenib combine with TMZ in the treatment of HCC.

Methods: In HCC cells, MAPK/ERK signaling pathway was blocked by U0126 and sorafenib. The effect of blocking MAPK/ERK signaling pathway on TMZ-induced cytotoxicity was evaluated by MTT assay, flow cytometry and TUNEL assay. DNA damage protein and the expression of MGMT were detected by Western-blot. After the downregulation of MAPK/ERK signaling pathway, MGMT mRNA expression and the protein expression of MGMT were quantified by quantitative real-time polymerase chain reaction (RTqPCR) and immunofluorescence assay, respectively. HepG2 cells were transfected with an MGMT over expression plasmid. After transfection, the effect of U0126 on TMZ-induced cytotoxicity was evaluated by MTT and Western-Blot in MGMT OE cells. The influence of Sorafenib on TMZ-induced cytotoxicity to HCC cells was also detected by MTT assay.

Results: U0126 can enhance the chemosensitivity of HCC cells to TMZ. At the same time, we also found that U0126 increases the damage to DNA caused by TMZ in HepG2 cells. Moreover, the results from RTqPCR and Western blot showed that U0126 downregulated MGMT mRNA and MGMT protein expression via blocking MAPK/ERK pathway. Furthermore, after transfection with an MGMT expression plasmid, overexpression of MGMT restored U0126-induced chemosensitivity to TMZ in HCC cells. Sorafenib can also increase the chemosensitivity of HCC cells to TMZ.

Conclusions: Our studies suggest great clinical potential for the utilization of combined U0126 and TMZ in patients with advanced HCC.

Keywords: Hepatocellular carcinoma (HCC); mitogen-activated protein kinase/extracellular signal regulated kinase pathway (MAPK/ERK pathway); temozolomide (TMZ); chemosensitivity; methylguanine-DNA methyltransferase (MGMT); sorafenib 
Submitted Jul 23, 2020. Accepted for publication Oct 19, 2020.

doi: $10.21037 /$ atm-20-5478

View this article at: http://dx.doi.org/10.21037/atm-20-5478

\section{Introduction}

Hepatocellular carcinoma (HCC) is the most common of the malignant tumors and ranks second in tumor-related mortality (1). Currently, the therapeutic strategies for patients with early-detected HCC include surgical resection or liver transplantation. Because there are no symptoms in the early stage of this disease, patients with advanced HCC are more common. For HCC diagnosed at advanced stages, chemotherapy has remained the treatment of choice, although, with a median survival rate of about 1 year (2), its therapeutic effect has not been satisfactory. In the past few years, great progress has been made in the treatment of HCC, but the long-term overall survival (OS) time of patients has remained unchanged (3). Thus, there has been an urgent search for new, effective drugs in HCC treatment informed by an understanding of the mechanism of HCC progression.

With the development of related medical technology in recent years, many molecular targeted agents have been developed for the treatment of advanced HCC, including epidermal growth factor receptor tyrosine kinase inhibitors, vascular endothelial growth factor receptor (VEGFR) antagonists, TGF- $\beta$ receptor inhibitors, multiple kinase inhibitors, and others. Of these, Sorafenib has been approved as a first-line treatment for advanced HCC by the Food and Drug Administration (FDA). Sorafenib acts as a multi-target and multi-kinase inhibitor. It can directly suppress tumor growth by inhibiting the RAF/ MEK/ERK signal pathway, block VEGFR and plateletderived growth factor receptor (PDGFR), interrupt tumor angiogenesis, and thus may indirectly inhibit tumor cell growth. Unfortunately, patients develop resistance and succumb to the disease after the application of Sorafenib for a period of time. Increasing evidence suggests that the activation of an escape pathway from RAF/MEK/ERK results in resistance (4). Tong et al. found that cobimetinib, a MEK inhibitor, is effective in overcoming resistance to Sorafenib (5). Still, treatment strategies utilizing mitogenactivated protein kinase/extracellular signal regulated kinase (MAPK/ERK) inhibitors alone have a high risk of resistance development. MAPK/ERK signaling pathway is not only involved in regulating cell biological functions, such as proliferation, differentiation, apoptosis, and angiogenesis, but also participates in tumor formation (6). Ras, Raf, MEK, and ERK proteins are the key factors in this signaling pathway. Abnormal function of any of these proteins can lead to serious tumor diseases. Ito et al. showed that in $58 \%$ of HCC cases, Ras/Raf/MEK/ERK signaling pathway is abnormally activated, and its related gene expression is upregulated (7). Despite there were sorts of studies investigating MAPK/ERK pathway as well as ERK inhibitors in hepatocellular carcinoma, rarely researches focus on ERK inhibitor combine with chemo drugs. Limited literature had mentioned that ERK pathway could induce drug resistance via multiple drug resistance manner by up regulating MDR in HCC cells $(8,9)$. However, DNA damage repair, another important drug resistance related system was not reported to involve in ERK pathway in HCC in previously investigations.

Temozolomide (TMZ) is an imidazotetrazine derivative of the alkylating agent dacarbazine, and can induce G2/ $M$ arrest in cell cycle, eventually leading to apoptosis. The mechanism of cytotoxicity induced by TMZ involves adding methyl groups to the N7 and O6 positions of guanines and $\mathrm{O} 3$ site of adenines in the genomic DNA, resulting in the insertion of a thymine instead of a cytosine in the subsequent DNA replication, which causes cytotoxicity. TMZ is widely used in chemotherapy for cancer. However, tumors quickly develop resistance to TMZ. The main mechanism of $\mathrm{TMZ}$ resistance is O6-methylguanineDNA methyltransferase (MGMT) overexpression. MGMT is an important effector molecule in the DNA damage repair (DDR) system. MGMT encodes the 207-amino acid protein, which possess a molecular weight of $170 \mathrm{kd}$. Cysteine residue in the fourth exon of MGMT gene is an alkyl receptor, which is the activation site of the protease. MGMT, as a DNA repair protein, is mainly responsible for repairing DNA alkylation or methylation damage. A study showed that the MEK inhibitors, SL327 and U0126, suppressed the expression of MGMT in glioblastoma multiforme (GBM) by downregulating MAPK/ERK pathway and activating $\mathrm{p} 53$ (10). This evidence indicated that MAPK/ERK inhibitors could applicated as chemo drug sensitizer. However, whether MAPK/ERK inhibitors could sensitize TMZ to HCC cells was still unveiled. Different 
from sorafenib which could inhibit multiple kinase cascade in cells, U0126 is a specific MAPK/ERK inhibitor, and widely utilized in MAPK/ERK pathway related cancer researches $(11,12)$. As it is unclear whether MAPK/ERK inhibition can sensitize HCC to TMZ, our research aimed to investigate the effect and potential mechanism of U0126 and sorafenib induced MAPK/ERK blocking on TMZ sensitivity in HCC cells. We present the following article in accordance with the MDAR reporting checklist (available at http://dx.doi.org/10.21037/atm-20-5478).

\section{Methods}

\section{Cell culture}

The human hepatocellular cell lines HepG2, Huh7, SMCC7721, and MHCC-97H were purchased from Shanghai Cell Bank of the Chinese Academy of Sciences (Shanghai, China). Cells were cultured in Dulbecco's modified Eagle's medium (DMEM, \#SH30022.01B, HyClone) supplemented with 10\% fetal bovine serum (FBS, \#11011-8615, Every Green) and antibiotics (penicillin $100 \mathrm{U} / \mathrm{mL}$, streptomycin $100 \mu \mathrm{g} / \mathrm{mL}$ ) at $37{ }^{\circ} \mathrm{C}$ in a humidified atmosphere with $5 \%$ $\mathrm{CO}_{2}$.

\section{General reagents}

TMZ was purchased from Leyan (Shanghai, China) and was stored as a $100 \mathrm{mM}$ stock solution in dimethyl sulfoxide (DMSO) (cell culture grade; Solarbio) at $-80{ }^{\circ} \mathrm{C}$. U0126 was obtained from Selleck Chemicals (Houston, TX, USA) and was stored as a $1 \mathrm{mM}$ stock solution in DMSO at $-80{ }^{\circ} \mathrm{C}$. Sorafenib was acquired from Solarbio (Beijing, China) and was stored as a $10 \mathrm{mM}$ stock solution in DMSO at $-20^{\circ} \mathrm{C}$. Antibodies to MGMT, $\gamma$-H2AX, p-ATR, p-ATM, and $\beta$-actin were purchased from Cell Signaling Technology (CST; Beverly, MA, USA). Secondary antibodies to HRP Goat Anti-Rabbit IgG $(\mathrm{H}+\mathrm{L})$ and HRP Goat Anti-Mouse IgG $(\mathrm{H}+\mathrm{L})$ were acquired from ImmunoWay Biotechnology Company (Plano, TX, USA).

\section{Plasmid vector and transfection}

Overexpression plasmid vector containing the full length of the DNA sequence coding for amino acids in MGMT protein was synthesized by Sangon Biotech (Shanghai) Co., Ltd. Sanger sequencing was employed to confirm the DNA sequence of MGMT. Plasmid was transfected using
Lipofectamine ${ }^{\mathrm{TM}} 2000$ transfection reagent (Invitrogen) following the manufacturer's protocols. Transfection efficiency of the HepG2 cells was identified by fluorescence microscopy.

\section{MTT assay}

MTT was purchased from Solarbio (Beijing, China). MTT assay was used to determine the cell viability following the manufacturer's protocols (Beijing Solarbio Science \& Technology Co., Ltd., China). All cells were seeded in 96-well plates at a density of 2,500 cells/well. The cells were cultured in $100 \mu \mathrm{L}$ of the medium with indicated concentrations of TMZ, U0126, or Sorafenib, alone or in combination, and incubated for 24, 48, and $72 \mathrm{~h}$ respectively. Then, $20 \mu \mathrm{L}$ of MTT solution $(5 \mathrm{mg} / \mathrm{mL})$ was added to every well and incubated for $3 \mathrm{~h}$ at $37^{\circ} \mathrm{C}$. Next, the media was removed and $200 \mu \mathrm{L}$ of DMSO was add to each well to dissolve the formazan crystals. Cell viability was quantified by MultiSkan FC at a wavelength of $570 \mathrm{~nm}$. The experimental results were recorded, and the inhibition rate and IC50 value were calculated. The growth inhibition rate was calculated as follows: growth inhibition rate $=$ (1 - A570 value of the drug treated group/A570 value of the control untreated group) $\times 100 \%$.

\section{Annexin V-FITC/PI staining}

Annexin V-FITC/PI Apoptosis Detection Kit was acquired from Signalway Antibody (College Park, MD, USA). HepG2 cells were seeded in a $6-\mathrm{cm}$ dish at a density of $2.5 \times 10^{6} \%$ dish and incubated overnight. The cells were divided into the following groups: control (untreated), U0126-treated, TMZ-treated, and U0126 + TMZ-treated cells. Cells were treated separately with $4 \mu \mathrm{M}$ of U0126 and $2 \mathrm{mM}$ of TMZ, alone or in combination, and incubated for 8 and $24 \mathrm{~h}$. After treatment, cells were collected and assayed as follow: The number of apoptotic cells was counted utilizing an Annexin V-FITC/PI Apoptosis Detection Kit (Signalway Antibody; College Park, MD, USA) according to the manufacturer's protocol. Apoptosis cells were analyzed by flow cytometry (Beckman, CA, USA). Annexin V-positive cells were defined as apoptotic cells. The percentage of HepG2 cell apoptosis was determined by three independent experiments.

\section{TUNEL staining}

Colorimetric TUNEL Apoptosis Assay Kit was acquired 
from Beyotime (Shanghai, China). SMCC-7721 cells were seeds into a 12 -well plate at a density of $4 \times 10^{5} /$ well and incubated for $12 \mathrm{~h}$. After cells were treated with $4 \mu \mathrm{M}$ U0126 and $2 \mathrm{mM}$ TMZ, alone or in combination for $4 \mathrm{~h}$. Cells were washed one time with PBS, fixed with $4 \%$ paraformaldehyde for $15 \mathrm{~min}$, treated with $0.3 \%$ Triton $\mathrm{X}-100$ in PBS for $5 \mathrm{~min}$, and subsequently incubated with $0.3 \%$ hydrogen peroxide for 20 min to block endogenous peroxide at room temperature. The DNA of apoptotic cells was labeled with the TUNEL reaction mixture according to the instructions provided by the manufacturer. Cells were photographed under the light microscope (Olympus, Japan).

\section{Quantitative real-time polymerase chain reaction (RT-qPCR)}

HepG2 cells were seeded in a $6-\mathrm{cm}$ dish at a density of $2.5 \times 10^{6} \%$ dish and incubated overnight. The cells were divided into control (untreated), $4 \mu \mathrm{M}$ U0126treated, and $8 \mu \mathrm{M}$ U0126-treated cells) and incubated for 8,24 , and $48 \mathrm{~h}$. Then, total RNA was isolated from these cells utilizing TRIzol ${ }^{\circledR}$ Reagent (Invitrogen, USA) following the manufacturer's protocol. Reverse transcription was conducted with RT reagent named " $5 \times$ all in one" (Applied Biological Materials, Richmond, BC, Canada). PCR was performed with EvaGreen ${ }^{\circledR}$ (Applied Biological Materials, Richmond, BC, Canada). The primers for MGMT were the following: forward primer, 5'-GTTTTCCAGCAAGAGTCGTTC-3'; reverse primer, 5'-GCTGCTAATTGCTGGTAAGAAA-3'. The primers for $\beta$-actin were the following: forward primer, $5^{\prime}$-CCT GGC ACC CAG CAC AAT-3'; reverse primer, 5'-GGG CCG GAC TCG TCA TAC-3'. The expression of $\beta$-actin was measured as an internal reference gene. All reactions were repeated three times independently. We used the $2^{-\Delta \Delta \mathrm{Cq}}$ method to analyze experimental data.

\section{Western blotting}

According to experimental needs, cells were treated with the designated drugs in advance. Cells were lysed with radioimmunoprecipitation assay (RIPA) buffer (high) containing $0.1 \%$ protease inhibitor cocktail (Solarbio; Beijing, China), and proteins were collected. The protein concentration was detected utilizing BCA Protein Assay kit (Beyotime Institute of Biotechnology). The proteins quantified were subjected to sodium dodecyl sulfate polyacrylamide gel electrophoresis (SDS-PAGE) and separated proteins were transferred to a polyvinylidene difluoride filter (Immobilon-P; Millipore, Billerica, MA, USA). The filters were blocked using $5 \%$ nonfat milk (Mengniu, Beijing, China) at room temperature for $2 \mathrm{~h}$. Primary antibodies against MGMT (CST; 1:2,000), p-ATR (CST; 1:1,000), p-ATM (CST; 1:1,000), $\gamma$-H2AX (CST; $1: 1,000)$, and $\beta$-actin (CST; $1: 10,000)$ were added to filters and incubated overnight at $4{ }^{\circ} \mathrm{C}$. The filters were washed three times with phosphate-buffered saline with Tween (PBST) for 10 min each and incubated with appropriate secondary antibodies to HRP Goat anti-Rabbit IgG $(\mathrm{H}+\mathrm{L})$ or HRP Goat anti-Mouse IgG $(\mathrm{H}+\mathrm{L})$ (ImmunoWay; $1: 10,000)$ at room temperature for $60 \mathrm{~min}$. Detection was performed with Immobilon Western Chemiluminescent HRP Substrate (Millipore Corporation, Billerica, MA, USA). Protein expression was quantified with ImageJ software (National Institutes of Health, Bethesda, MD, USA).

\section{Immunofluorescence}

Coverslips were placed into 6-well plates in advance. HepG2 cells $\left(2 \times 10^{5}\right)$ were seeded onto the coverslips and incubated overnight. The cells were divided into the following groups: control (untreated), TMZ-treated, U0126-treated, and U0126 + TMZ-treated cells. HepG2 cells were exposed to $\mathrm{U} 0126(8 \mu \mathrm{M})$ and TMZ $(1 \mathrm{mM})$, alone or in combination, for $24 \mathrm{~h}$. Cells were washed three times with PBS for $3 \mathrm{~min}$ each. The cells were fixed with $4 \%$ paraformaldehyde for $30 \mathrm{~min}$ at room temperature, treated with $0.2 \%$ Triton $\mathrm{X}-100$ in PBS for $15 \mathrm{~min}$ at room temperature, and were then blocked with $5 \%$ bovine serum albumin (BSA) for $60 \mathrm{~min}$ at room temperature. The cells were incubated overnight with primary antibody MGMT (CST; 1:100) or $\gamma$-H2AX (CST; 1:100) diluted in PBST at $4{ }^{\circ} \mathrm{C}$. Then, cells were incubated with CoraLite 594-conjugated Goat AntiRabbit IgG $(\mathrm{H}+\mathrm{L})$ secondary antibody (Proteintech; 1:400) for $60 \mathrm{~min}$ at room temperature protected from light. The coverslips were blocked by antifading mounting medium, (with DAPI). Cells were observed and photographed by fluorescence microscope (IX5 Observer Inverted Microscope; Olympus, Tokyo, Japan).

\section{Statistical analysis}

Graphpad Prism 8 (version 8.02; GraphPad Inc., San Diego, CA, USA) was used to determine IC50. Graphpad Prism 
8 (version 8.02; GraphPad Inc., San Diego, CA, USA) and IBM SPSS Statistics (SPSS version 26.0) were used to analysis all statistical data through one-way analysis of variance (ANOVA), two-way ANOVA, and Student's $t$-test. The significance levels were set at ${ }^{*} \mathrm{P}<0.05$ and ${ }^{*} \mathrm{P}<0.01$.

\section{Results}

\section{U0126 improved the chemosensitivity of HCC cells to TMZ}

To investigate whether U0126 can increase the chemosensitivity of HCC cells to TMZ, cell inhibition was determined by MTT assay by logarithmically growing HepG2, Huh7, MHCC-97H, and SMCC-7721 HCC cells treated with various concentration of U0126 (2, 4, 8, and $16 \mu \mathrm{M})$ and/or TMZ (0.5, 1.0, 1.5, 2.0, 2.5, and $3.0 \mathrm{mM})$ for 24, 48, and $72 \mathrm{~h}$ (Figure 1). Treatment with TMZ alone inhibited cell growth in a dose- and time-dependent manner. As a shown Figure 1, combined treatment with U0126 and TMZ increased the inhibition rate of cells compared to TMZ. The IC50 value of the TMZ + U0126 group was smaller than that of the TMZ group (Tables 1-4). These results provide direct evidence that U0126 enhances the chemosensitivity of HCC cells to TMZ in a dosedependent manner.

\section{U0126 enhanced TMZ-induced apoptosis}

Apoptotic cells were detected when HepG2 cells were treated with U0126 $4 \mu \mathrm{M}$ and TMZ $2 \mathrm{mM}$, alone or in combination, by PI/Annexin V staining (Figure $2 A$ ). Following treatment with $2 \mathrm{mM}$ of TMZ for $8 \mathrm{~h}$, the apoptotic rate increased from $7.63 \% \pm 1.79 \%$ in the control group to $12.00 \% \pm 1.92 \%$ in the TMZ $2 \mathrm{mM}$ group. Treatment with $2 \mathrm{mM} \mathrm{TMZ}$ in combination with $4 \mu \mathrm{M}$ U0126 for $8 \mathrm{~h}$ increased the apoptotic rate to $32.43 \% \pm 2.41 \%$ compared with TMZ $2 \mathrm{mM}$ treatment alone. Following treatment with $2 \mathrm{mM}$ TMZ for $24 \mathrm{~h}$, the apoptotic rate increased from $7.17 \% \pm 1.88 \%$ in the control group to $28.43 \% \pm 0.85 \%$ in the TMZ $2 \mathrm{mM}$ group. Treatment with $2 \mathrm{mM} \mathrm{TMZ}$ in combination with $4 \mu \mathrm{M}$ U0126 for $24 \mathrm{~h}$ increased the apoptotic rate to $36.37 \% \pm 3.23 \%$ compared with TMZ $2 \mathrm{mM}$ treatment alone. For both the 8 - or 24 -h durations, there was no significant difference between the U0126 $4 \mu \mathrm{M}$ group and the control group in the apoptotic rate $(\mathrm{P}>0.05)$. In addition, TUNEL staining was also used to evaluate apoptosis in SMCC-7721 cells. The cells were treated with U0126 $4 \mu \mathrm{M}$ and TMZ $2 \mathrm{mM}$, alone or in combination. As shown in Figure 2B, The TMZ $2 \mathrm{mM}$ group and TMZ $2 \mathrm{mM}+\mathrm{U} 01264 \mu \mathrm{M}$ group exhibited a significantly greater proportion of TUNEL-positive nuclei compared with those from the control group. What's more, there were more positive cells in TMZ $2 \mathrm{mM}+\mathrm{U} 01264 \mu \mathrm{M}$ group than TMZ $2 \mathrm{mM}$ group. The apoptosis results indicated that U0126 can increase TMZ-induced apoptosis.

\section{U0126 increased TMZ-induced DNA damage}

Protein expression levels of p-ATR, $\gamma$-H2AX, p-ATM, p-ERK1/2 and ERK1/2 were detected when HepG2 cells were treated with U0126 (4 and $8 \mu M)$ and/or TMZ $(1 \mathrm{mM})$ by Western blot analysis (Figure $3 A$ ). Western blot indicated that the p-ATR, $\gamma$-H2AX, and p-ATM protein expression levels in the TMZ + U0126 $4 \mu \mathrm{M}$ group and the TMZ + U0126 $8 \mu M$ group were increased compared with the control group and TMZ group. Furthermore, the protein expression levels of the TMZ + U0126 $8 \mu \mathrm{M}$ group increased more than those of the TMZ + U0126 $4 \mu \mathrm{M}$ group. The protein expression of p-ERK1/2 in the control group, the TMZ + U0126 $4 \mu M$ group and the $\mathrm{TMZ}+\mathrm{U} 01268 \mu \mathrm{M}$ group were decreased successively. Western blot results demonstrated that U0126 can suppress MAPK/ERK pathway and enhance TMZ-induced DNA damage in a dose-dependent manner. The subcellular localization and expression level of $\gamma-\mathrm{H} 2 \mathrm{AX}$ were determined by immunofluorescence staining (Figure 3B). Immunofluorescence staining results also showed that the expression of $\gamma-\mathrm{H} 2 \mathrm{AX}$ in the TMZ $1 \mathrm{mM}$ group and TMZ $1 \mathrm{mM}+\mathrm{U} 01268 \mu \mathrm{M}$ group was increased compared with the control group and the U0126 $8 \mu \mathrm{M}$ group. Moreover, the $\gamma-\mathrm{H} 2 \mathrm{AX}$ expression in the TMZ + U0126 $8 \mu \mathrm{M}$ group increased more than that in the TMZ $1 \mathrm{mM}$ group. These results indicate that U0126 can increase the DNA damage caused by TMZ. There results imply that U0126 increases apoptosis of HepG2 cells by increasing TMZ-induced DNA damage.

\section{MAPK/ERK patbway downregulation reduced MGMT expression in HCC cells}

U0126 inhibited MAPK/ERK signaling pathway and reduces MGMT mRNA and MGMT protein. Protein expression levels of MGMT were detected when HepG2, Huh7, MHCC-97H, and SMCC-7721 cells were treated 

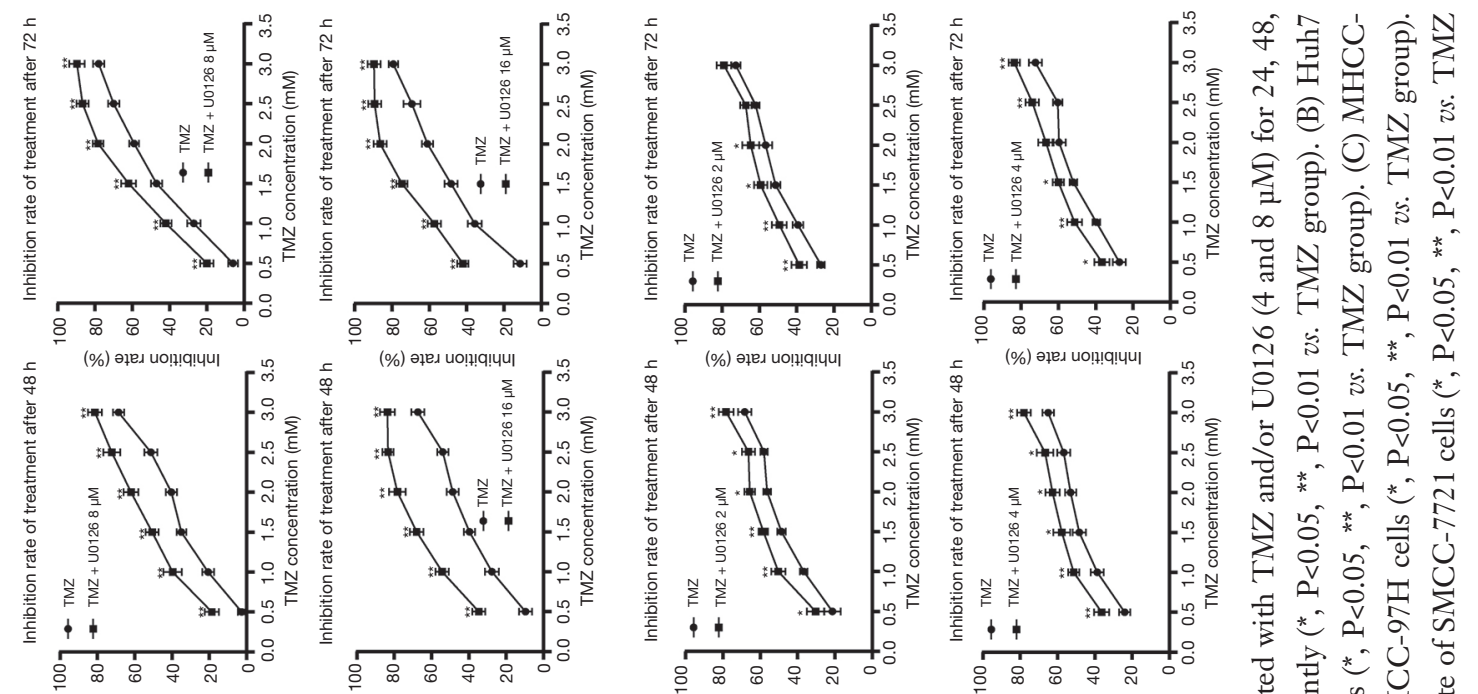

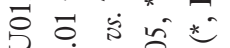
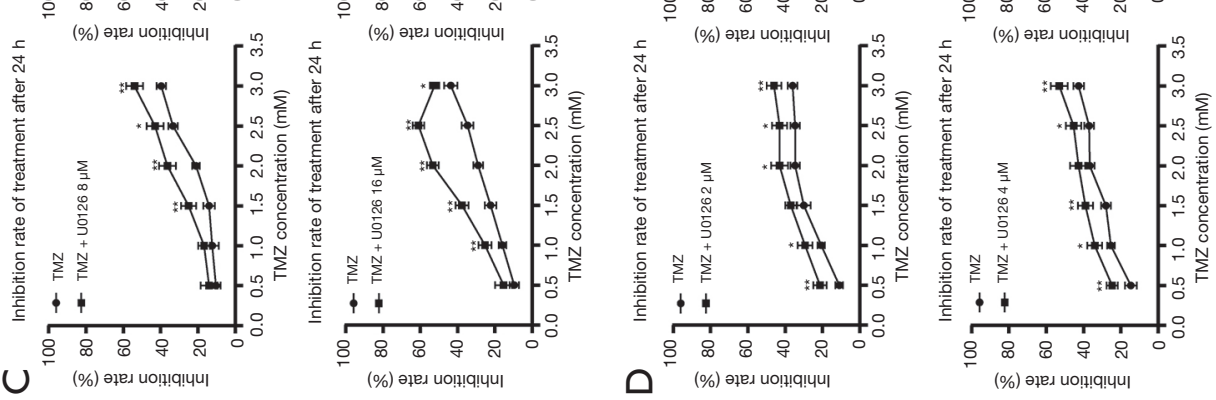

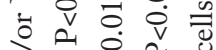

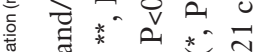

N

a

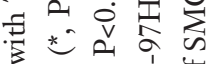
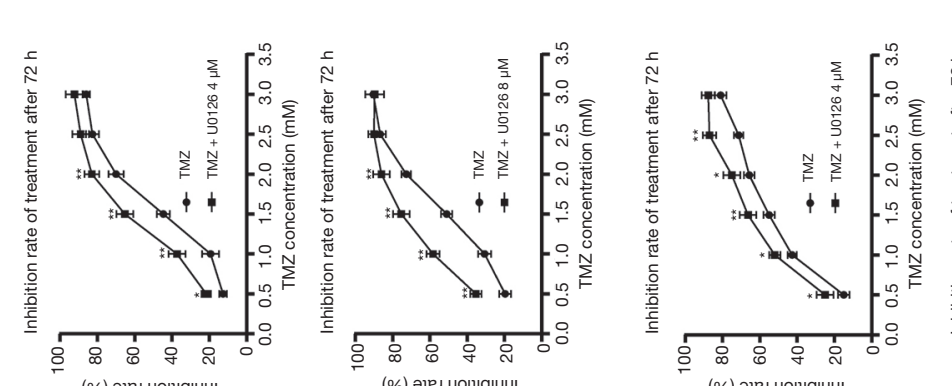

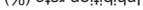

在

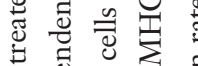
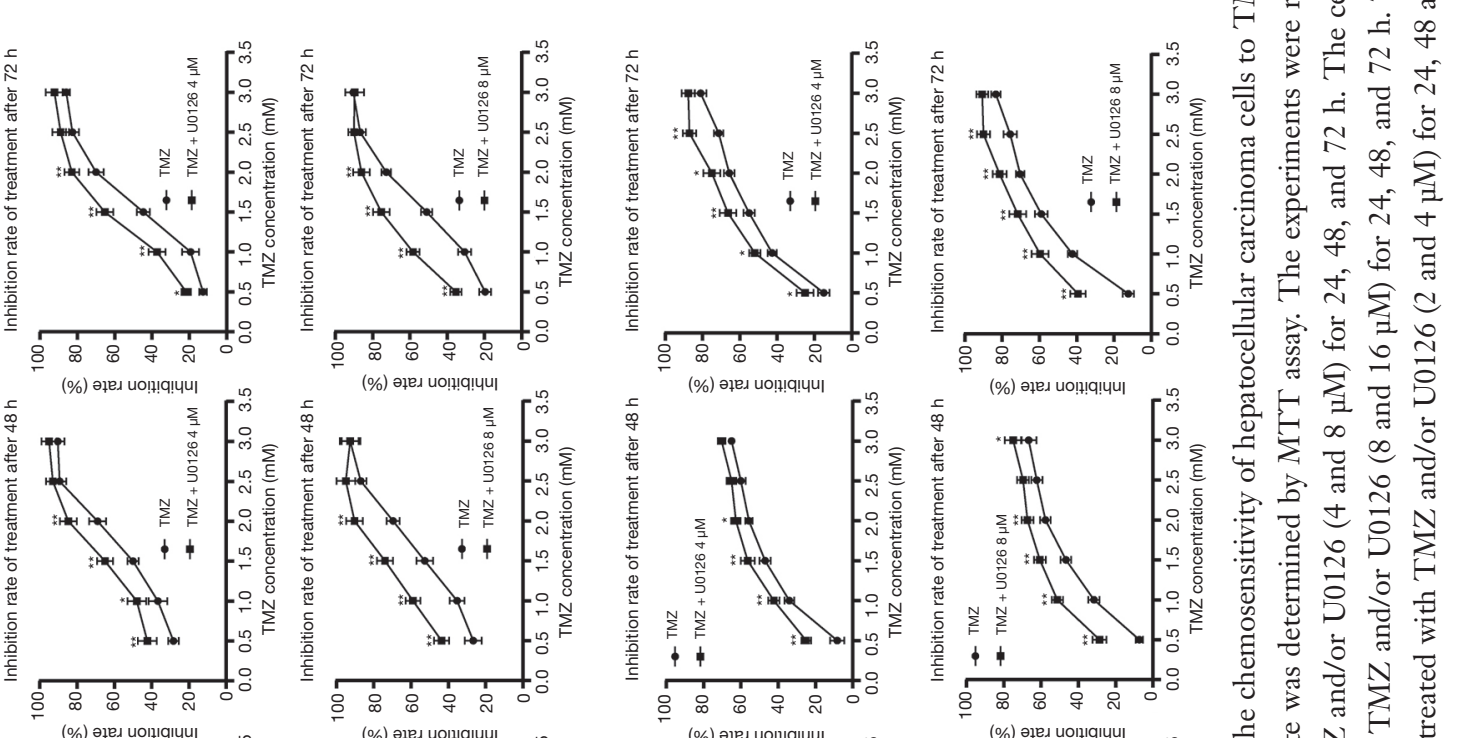

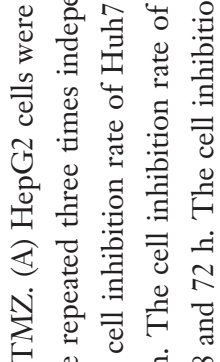

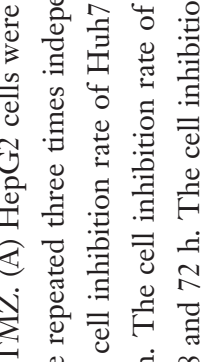

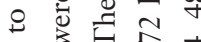
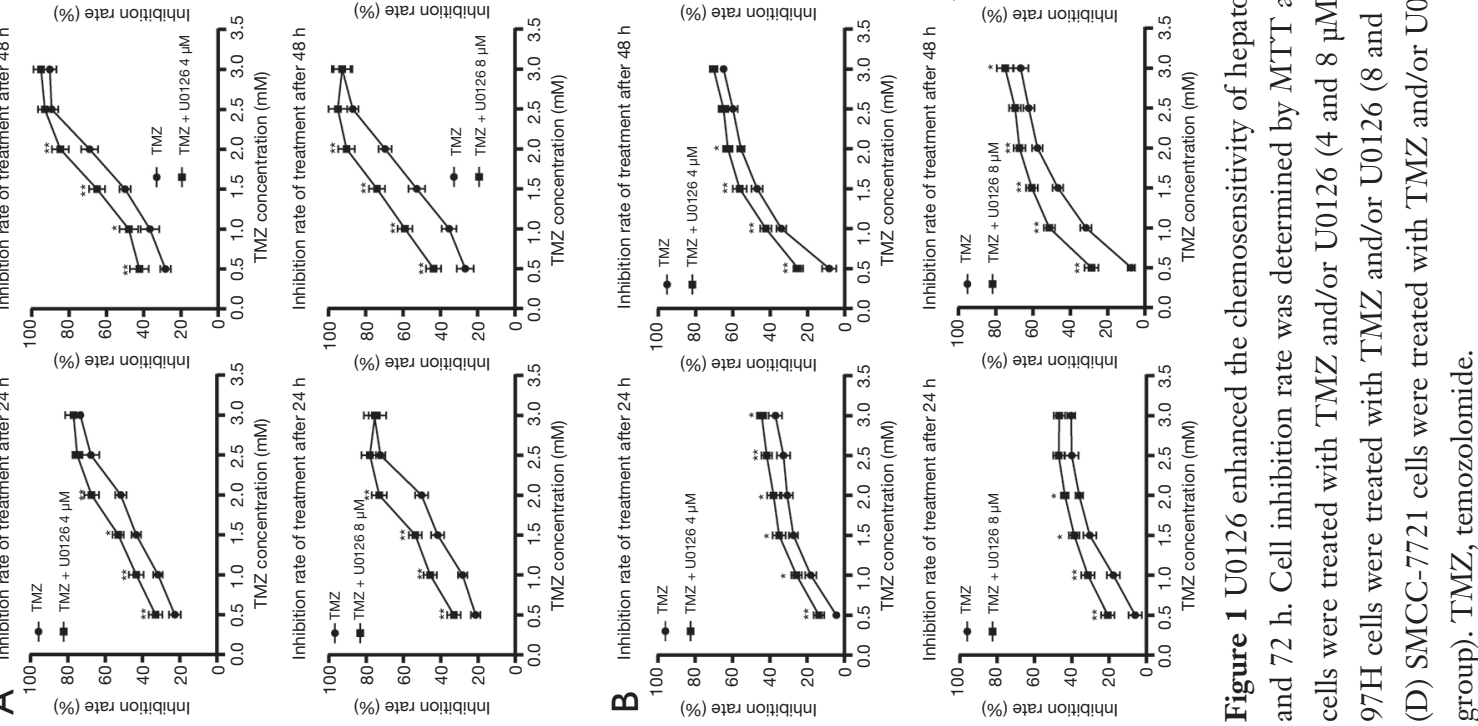
Table 1 The $\mathrm{IC}_{50}$ value of HepG2 cells (mM)

\begin{tabular}{lcccc}
\hline Time & TMZ & TMZ + U0126 $4 \mu M$ & $T M Z$ & $T M Z+U 01268 \mu M$ \\
\hline $24 \mathrm{~h}$ & 1.60 & 1.10 & 1.60 & 1.02 \\
$48 \mathrm{~h}$ & 1.12 & 0.78 & 1.13 & 0.67 \\
$72 \mathrm{~h}$ & 1.46 & 1.06 & 1.24 & 0.75 \\
\hline
\end{tabular}

$\mathrm{TMZ}$, temozolomide.

Table 2 The $\mathrm{IC}_{50}$ value of Huh7 cells (mM)

\begin{tabular}{lcccc}
\hline Time & TMZ & TMZ + U0126 $4 \mu \mathrm{M}$ & $\mathrm{TMZ}$ & $\mathrm{TMZ}+\mathrm{U} 01268 \mu \mathrm{M}$ \\
\hline $24 \mathrm{~h}$ & 4.43 & 3.63 & 3.58 & 3.14 \\
$48 \mathrm{~h}$ & 1.79 & 1.39 & 1.76 & 1.06 \\
$72 \mathrm{~h}$ & 1.32 & 0.97 & 1.27 & 0.72 \\
\hline
\end{tabular}

TMZ, temozolomide.

Table 3 The $\mathrm{IC}_{50}$ value of MHCC-97H cells (mM)

\begin{tabular}{lcccc}
\hline Time & TMZ & TMZ + U0126 $8 \mu \mathrm{M}$ & $\mathrm{TMZ}$ & $\mathrm{TMZ}+\mathrm{U} 012616 \mu \mathrm{M}$ \\
\hline $24 \mathrm{~h}$ & 5.92 & 3.20 & 4.47 & 2.15 \\
$48 \mathrm{~h}$ & 2.21 & 1.35 & 2.02 & 0.83 \\
$72 \mathrm{~h}$ & 1.64 & 1.09 & 1.50 & 0.69 \\
\hline
\end{tabular}

TMZ, temozolomide.

Table 4 The $\mathrm{IC}_{50}$ value of SMCC-7721 cells (mM)

\begin{tabular}{lcccc}
\hline Time & TMZ & TMZ + U0126 2 $\mu \mathrm{M}$ & $\mathrm{TMZ}$ & $\mathrm{TMZ}+\mathrm{U} 01264 \mu \mathrm{M}$ \\
\hline $24 \mathrm{~h}$ & 5.26 & 3.63 & 4.65 & 2.97 \\
$48 \mathrm{~h}$ & 1.63 & 1.07 & 1.69 & 0.98 \\
$72 \mathrm{~h}$ & 1.42 & 0.94 & 1.39 & 0.92 \\
\hline
\end{tabular}

TMZ, temozolomide.

with U0126 (0, 2, 4, and $8 \mu \mathrm{M})$ and/or TMZ $(1 \mathrm{mM})$ for 8 h by Western blot (Figure $4 A, B, C, D$ ). Western blot analysis showed that the protein expression levels of MGMT in the control group, TMZ group, TMZ + U0126 $2 \mu \mathrm{M}$ group, $\mathrm{TMZ}+\mathrm{U} 01264 \mu \mathrm{M}$ group, and the TMZ + U0126 $8 \mu \mathrm{M}$ group decreased sequentially. Expression levels of MGMT mRNA were determined when HepG2 cells were treated with U0126 (4 and $8 \mu \mathrm{M}$ ) for 8 , 24, and $48 \mathrm{~h}$ by RT-qPCR (Figure 4E). The results indicated that U0126 can inhibit MGMT mRNA expression in a doseand time-dependent manner.

\section{MGMT overexpression attenuated the chemosensitizing effect of U0126 in HCC cells}

To explore the chemosensitizing effect of U0126 in HepG2 MGMT OE cells, we performed following experiment. First, MGMT overexpression plasmid was transfected into HepG2 cells to upregulate the expression of MGMT (Figure $5 A$ ). After transfection for $24 \mathrm{~h}$, HepG2 MGMT OE cells were treated with $4 \mu M$ U0126 and/or $1 \mathrm{mM} \mathrm{TMZ}$ for $36 \mathrm{~h}$, and the protein expression levels of MGMT were detected by Western blot analysis (Figure 5B). Western blot showed that the protein expression levels of MGMT OE-TMZ + 

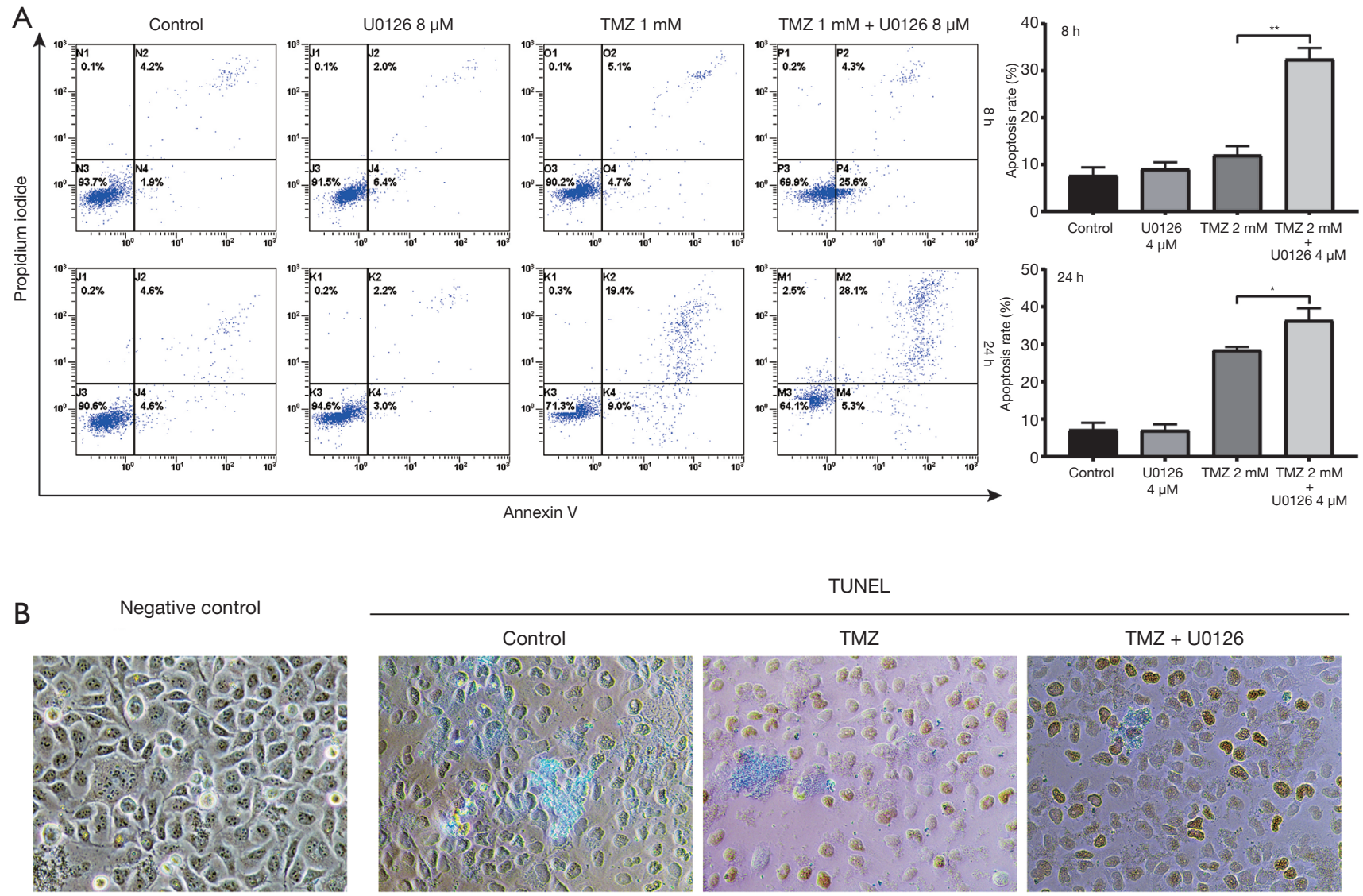

Figure 2 U0126 enhanced TMZ-induced apoptosis. (A) Apoptosis rate of HepG2 cells treated with U0126 and TMZ, alone or in combination, was analyzed by flow cytometry PI/Annexin V staining ( ${ }^{*}, \mathrm{P}<0.05$, ${ }^{* *}, \mathrm{P}<0.01$ the TMZ $2 \mathrm{mM}+\mathrm{U} 01264 \mu \mathrm{M} v$ s. the TMZ $2 \mathrm{mM}$ group). (B) TUNEL staining was performed for the evaluation of TMZ-induced apoptosis in SMCC-7721 cells. The nuclei of TUNEL-positive cells were stained brown $(\times 200)$. TMZ, temozolomide.

U0126 group increased more than those of the control$\mathrm{TMZ}+\mathrm{U} 0126$ group and the NC-TMZ + U0126 group. Furthermore, the results of MTT assays showed that the IC50 value of the MGMT OE-TMZ + U0126 group was significantly higher than that of the control-TMZ + U0126 group and the NC-TMZ + U0126 group (Figure $5 C)$. Our results indicate that MGMT overexpression attenuates the chemosensitizing effect of U0126.

\section{Sorafenib enhanced the chemosensitivity of HCC cells to TMZ by inbibiting MGMT expression}

To investigate whether Sorafenib can increase the chemosensitivity of HCC cells to TMZ, cell inhibition was determined by MTT assay by logarithmically growing HepG2, Huh7, MHCC-97H, and SMCC-7721 HCC cells treated with various concentrations of Sorafenib (1, 2, $4,8$, and $16 \mu \mathrm{M})$ and/or TMZ $(0.5,1.0,1.5,2.0,2.5$, and $3.0 \mathrm{mM}$ ) for 24,48 , and $72 \mathrm{~h}$ (Figure $6 A, B, C, D$ ). Treatment with TMZ alone inhibited cell growth in a dose- and time-dependent manner. As a shown Figure $6 A, B, C, D$, combined treatment with Sorafenib and TMZ increased the inhibition rate of cells compared to TMZ. The IC50 value of the TMZ + Sorafenib group was smaller than that of the TMZ group (Tables 5-8). Protein expression levels of MGMT, p-ERK1/2 and ERK1/2 were detected when HepG2 cells were treated with Sorafenib $(0,2,4$, and $8 \mu M)$ and/or TMZ $(1 \mathrm{mM})$ for $8 \mathrm{~h}$ by Western blot (Figure 7). Western blot analysis showed that the protein expression levels of MGMT in the control group, TMZ group, TMZ + Sorafenib $2 \mu M$ group, TMZ + Sorafenib $4 \mu M$ group, and TMZ + Sorafenib $8 \mu M$ group decreased sequentially. 

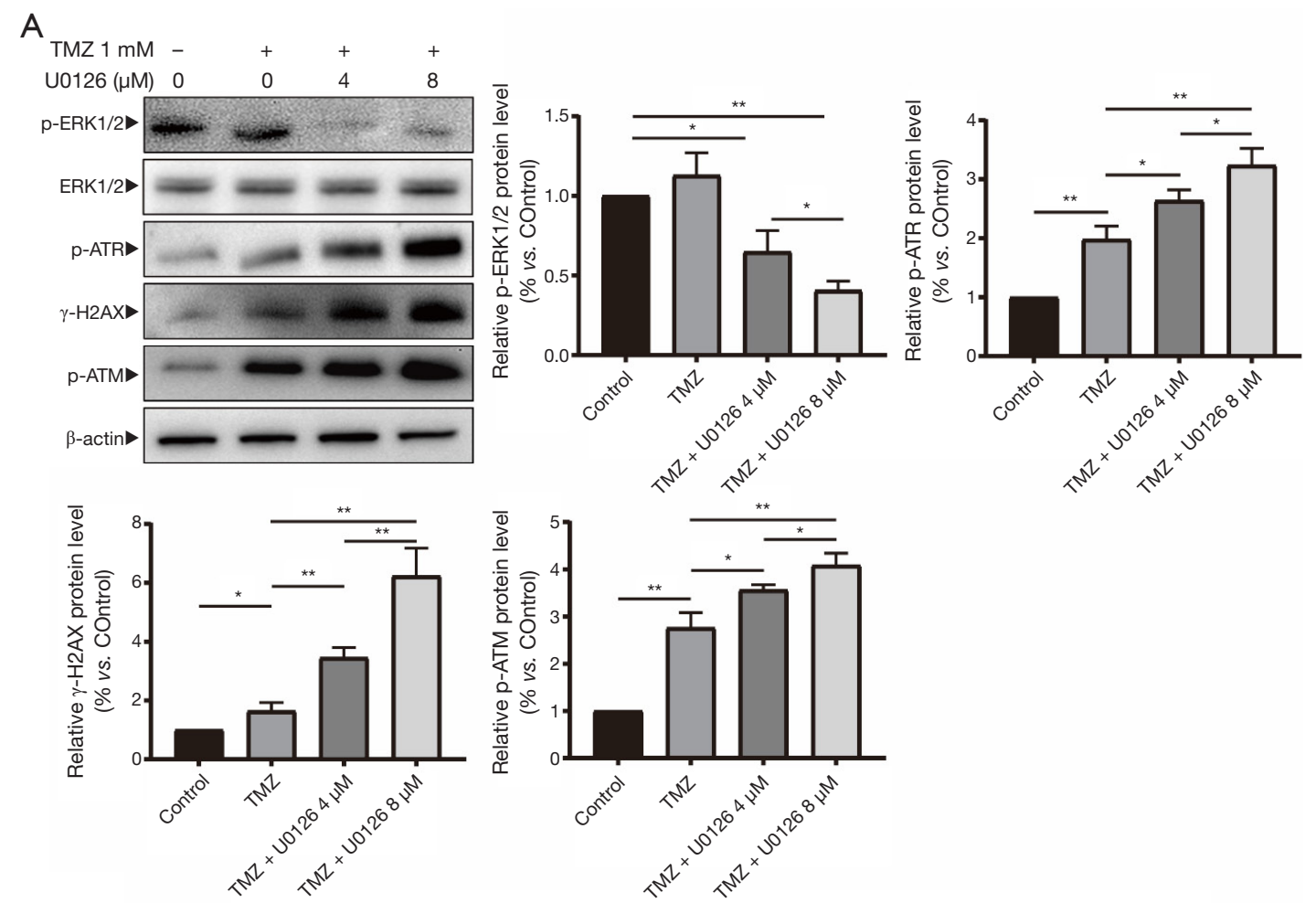

B
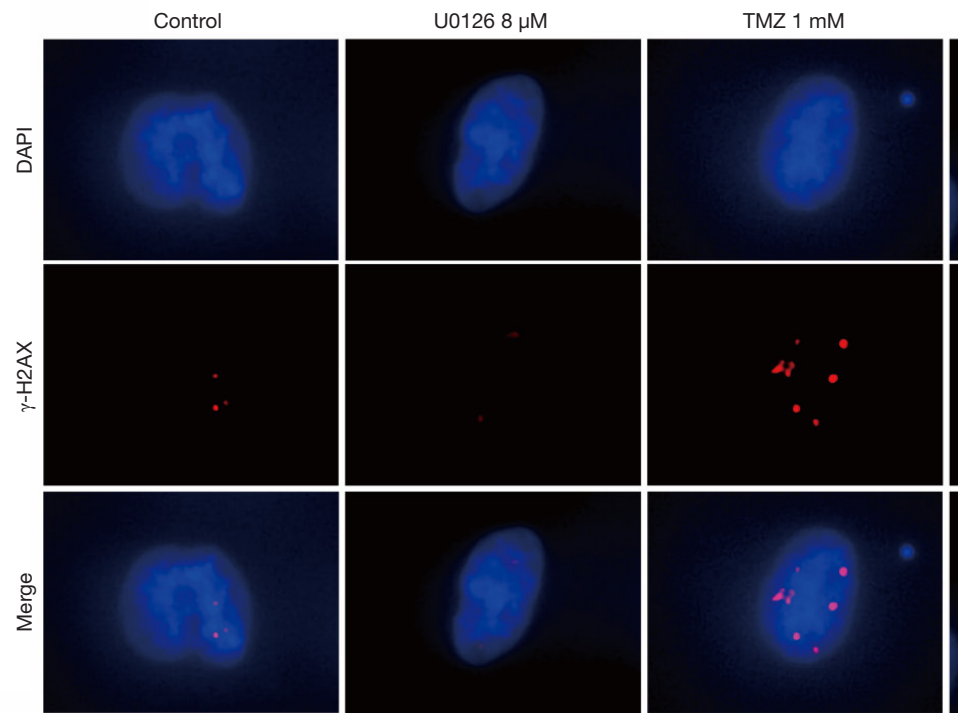

$\mathrm{TMZ} 1 \mathrm{mM}+\mathrm{U} 01268 \mu \mathrm{M}$

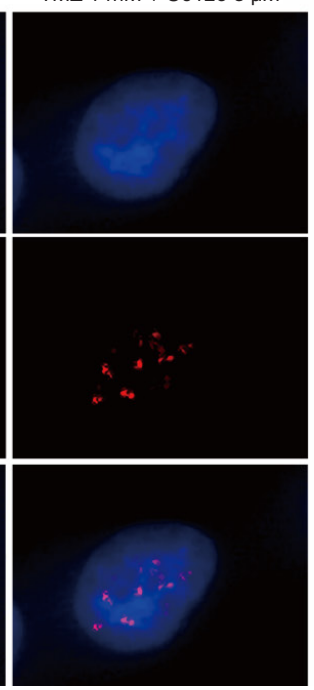

Figure 3 U0126 enhanced TMZ-induced DNA damage. (A) Protein expression levels of p-ATR, $\gamma$-H2AX, p-ATM, p-ERK1/2 and ERK1/2 were detected when HepG2 cells were treated with TMZ $(1 \mathrm{mM})$ and U0126 $(4$ and $8 \mu \mathrm{M})$ for 24 h by Western blot analysis $\left({ }^{*}, \mathrm{P}<0.05\right.$, **, $\mathrm{P}<0.01$ vs. the indicated treatment). TMZ, temozolomide. (B) Immunofluorescence staining analysis of HepG2 cells for $\gamma$-H2AX (red). DAPI (blue) was used to stain the nuclei (representative fields at $\times 200$ magnification). TMZ, temozolomide; MAPK/ERK, mitogen-activated protein kinase/extracellular signal regulated kinase pathway; MGMT, methylguanine-DNA methyltransferase. 

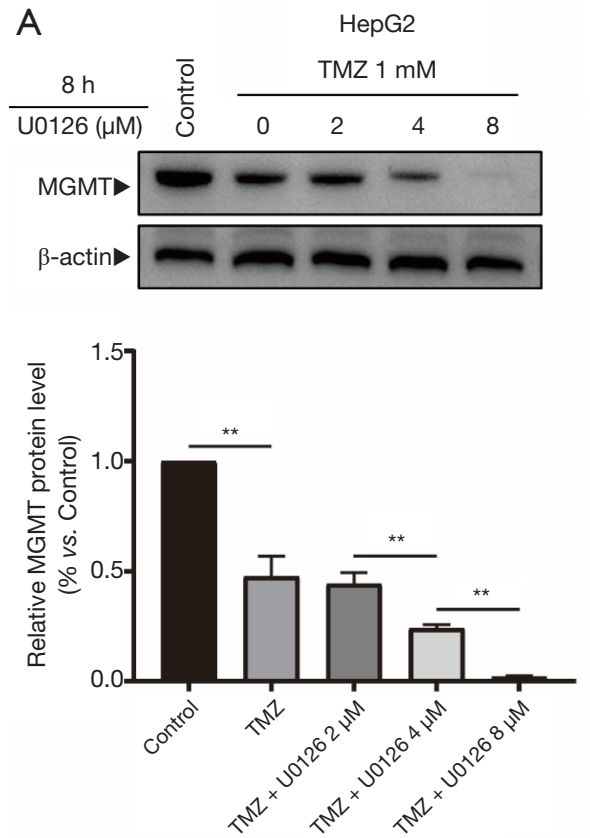

D
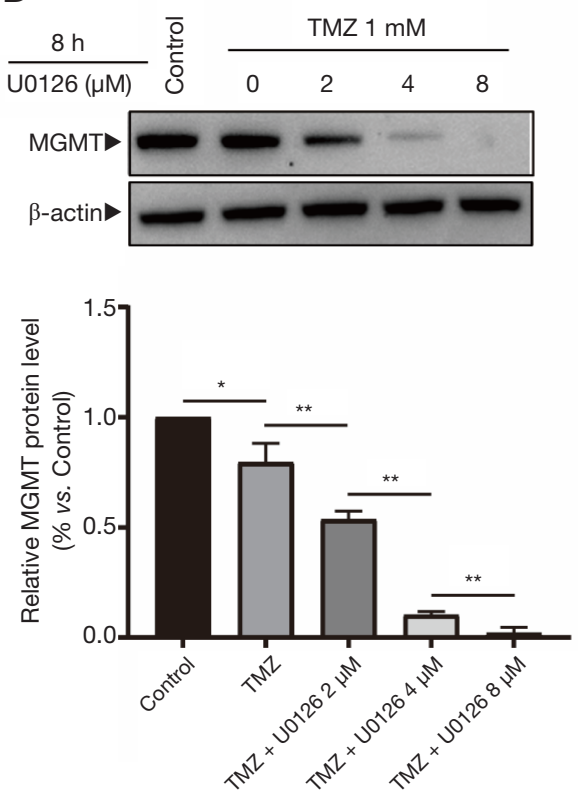
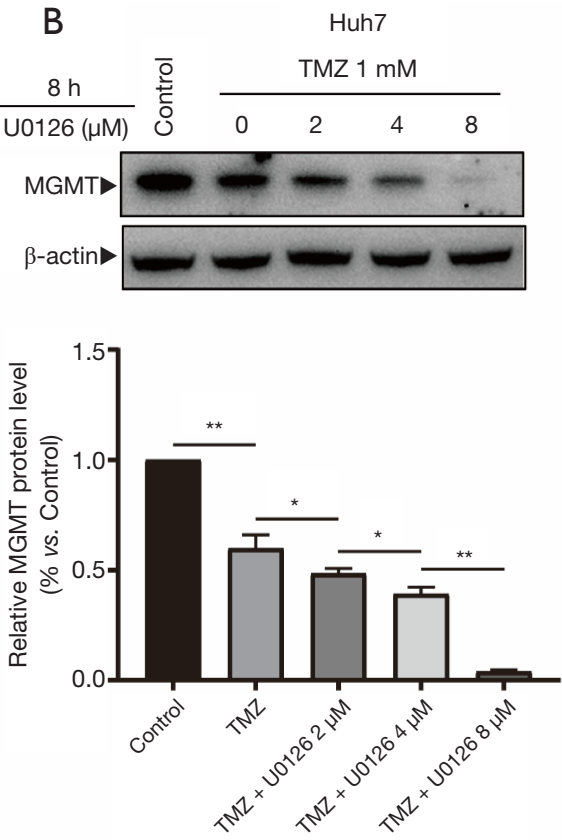

E

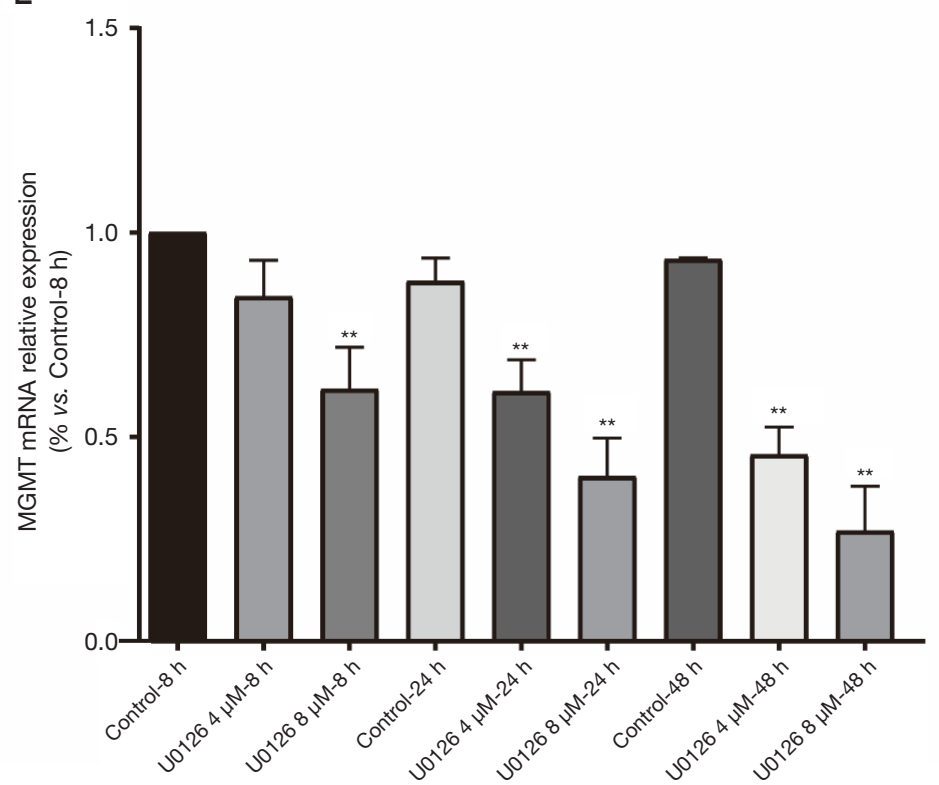

Figure 4 MAPK/ERK pathway downregulation reduced MGMT expression in hepatocellular carcinoma cells. (A) Protein expression levels of MGMT were detected when HepG2 cells were treated with TMZ (1 mM) and U0126 (2, 4, and $8 \mu \mathrm{M})$ for 8 h by Western blot analysis $\left({ }^{*}, \mathrm{P}<0.05,{ }^{* *}, \mathrm{P}<0.01\right.$ vs. the indicated treatment). (B) Protein expression levels of MGMT were detected when Huh7 cells were treated with TMZ $(1 \mathrm{mM})$ and $\mathrm{U} 0126(2,4$, and $8 \mu \mathrm{M})$ for $8 \mathrm{~h}$ by Western blot analysis (*, $\mathrm{P}<0.05,{ }^{* *}, \mathrm{P}<0.01$ vs. the indicated treatment). (C) Protein expression levels of MGMT were detected when MHCC-97H cells were treated with TMZ (1 mM) and U0126 (2, 4, and $8 \mu \mathrm{M})$ for $8 \mathrm{~h}$ by Western blot analysis (*, $\mathrm{P}<0.05$, **, $\mathrm{P}<0.01$ vs. the indicated treatment). (D) Protein expression levels of MGMT were detected when SMCC-7,721 cells were treated with TMZ $(1 \mathrm{mM})$ and $\mathrm{U} 0126(2,4$, and $8 \mu \mathrm{M})$ for $8 \mathrm{~h}$ by Western blot analysis $\left(^{*}, \mathrm{P}<0.05,{ }^{* *}, \mathrm{P}<0.01\right.$ vs. the indicated treatment). (E) RT-qPCR analysis of MGMT mRNA expression in HepG2 cells treated with U0126 (4 and $8 \mu M)$ for 8,24 , and $48 \mathrm{~h}\left({ }^{*}, \mathrm{P}<0.05,{ }^{* *}, \mathrm{P}<0.01\right.$ vs. control—8 h group). TMZ, temozolomide; MAPK/ERK, mitogen-activated protein kinase/extracellular signal regulated kinase pathway; MGMT, methylguanine-DNA methyltransferase. 

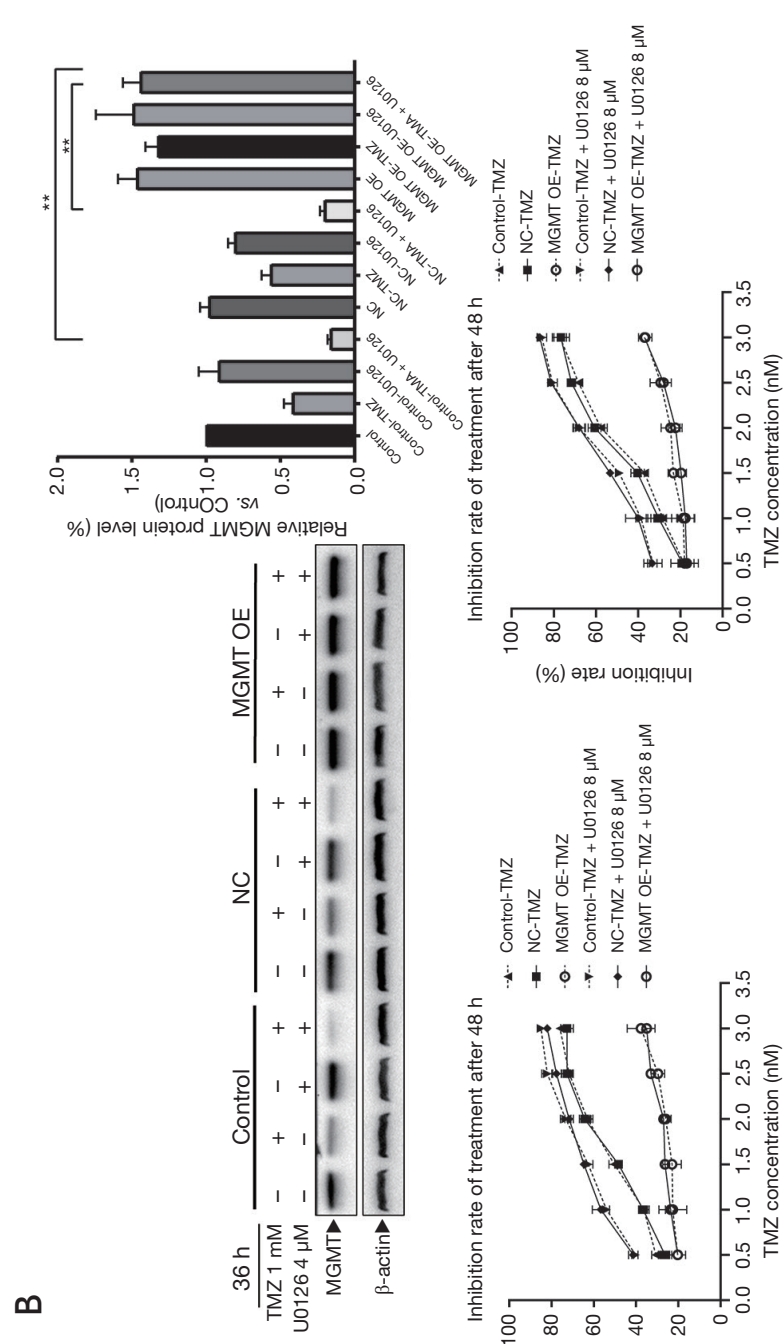

(\%) әрех ио!!!q!4u।

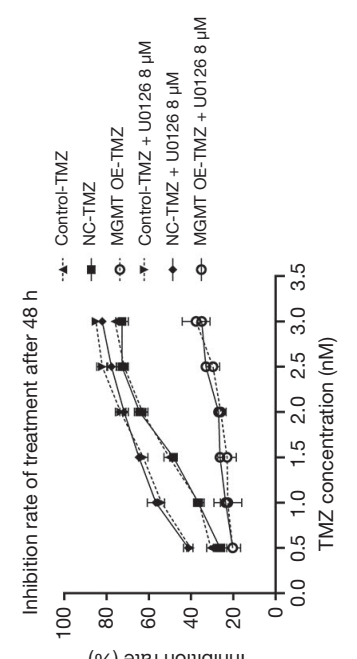

(\%) әңеג uo!!!q!पu।
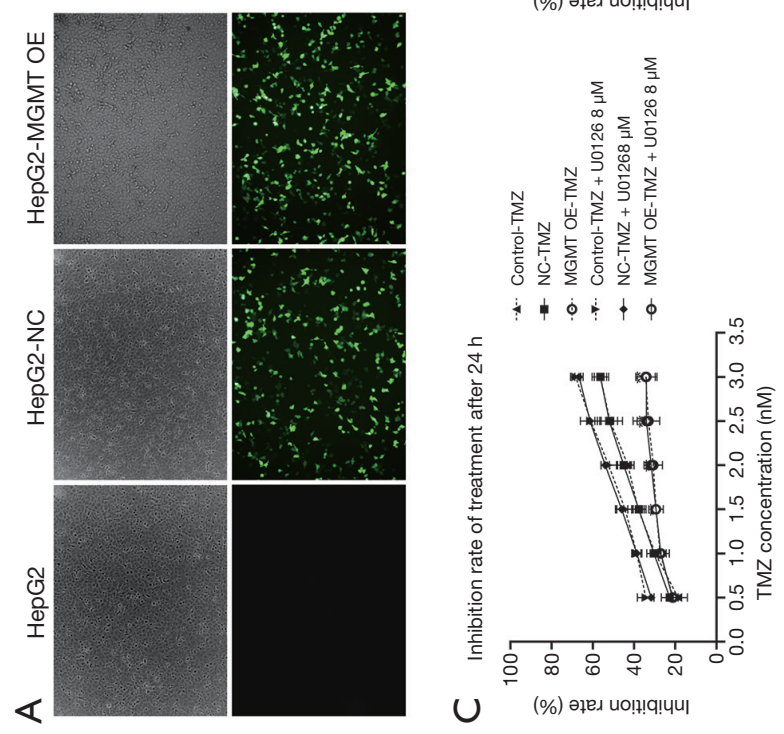

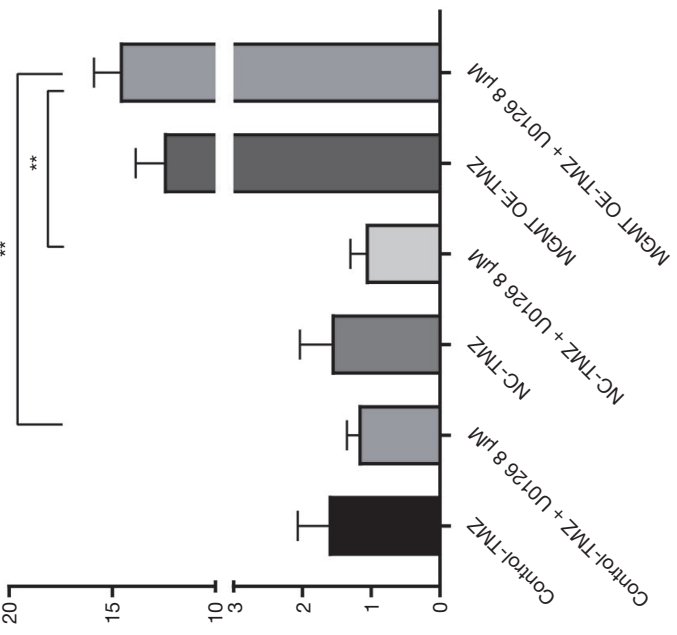

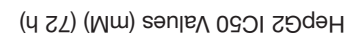

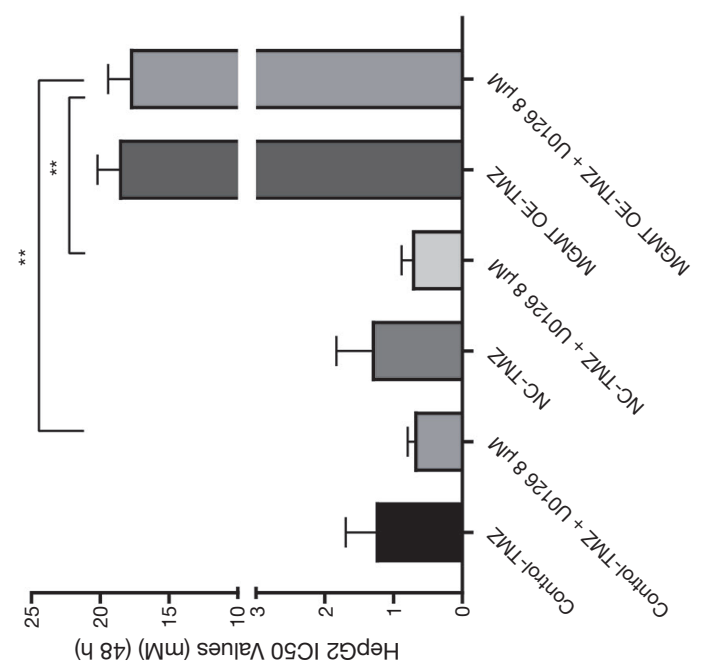

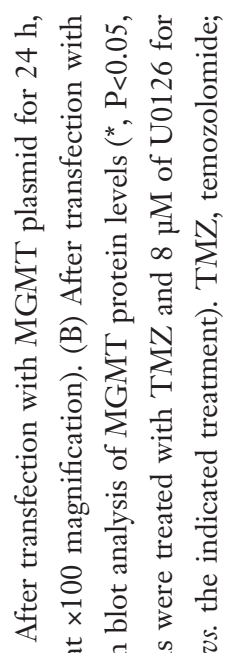

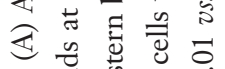

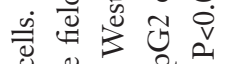

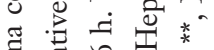

च

m

c 0

충

证

造的

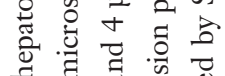

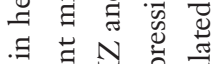

寻苞式

亏

岁吉表年

药定

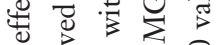

कo

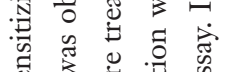

ष

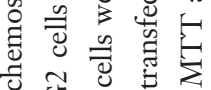

० 을

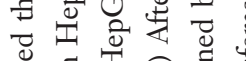

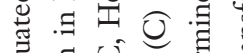

氙击

范苛

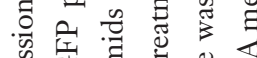

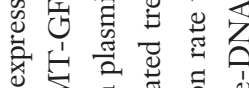

空点离吉

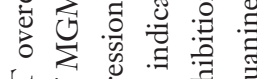

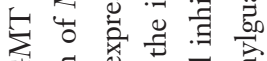

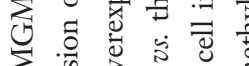

in

深

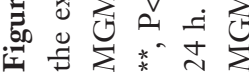


The protein expression levels of p-ERK1/2 in the control group, TMZ + Sorafenib $2 \mu M$ group, TMZ + Sorafenib $4 \mu M$ group and TMZ + Sorafenib $8 \mu M$ group decreased sequentially. These results provide direct evidence that Sorafenib can also enhance the chemosensitivity of HCC cells to TMZ in a dose-dependent manner by inhibiting MGMT expression.

\section{Discussion}

TMZ is an oral chemotherapy drug that can be quickly and completely absorbed after oral administration. TMZ does not directly play a cytotoxic role, but is rapidly converted into the active compound, 3-methyl-(triazine-1-)imidazole4-carboxamide (MTIC), by a non-enzymatic pathway at the physiological $\mathrm{pH}$ of the systemic circulation. The cytotoxic effect of MTIC is mainly manifested in the alkylation of the sixth oxygen atom of the guanine and the seventh nitrogen atom of the DNA molecule, which promotes DNA strand breaks and subsequent cell death by interfering with the continuous cycle of DNA replication. Therefore, the therapeutic effect of TMZ depends on its ability to alkylate and/or methylate DNA. However, tumor cells can repair DNA damage induced by TMZ, which limits the therapeutic effect and drives to drug resistance. The main mechanism of TMZ resistance includes the DNA repair system, which includes base excision repair (BER), mismatch repair (MMR), MGMT, and autophagy. The BER system involves multicatalytic reactions by endonuclease, DNA glycosylase, DNA ligase, and polymerase. The BER system can rapidly repair the methylation of N3-adenine and the N7-guanine caused by TMZ. Meanwhile, the MMR system can recognize the mismatch between O6-methylguanine (O6-MeG) and thymine during DNA replication, and excise this DNA strand. MGMT, as a DNA repair enzyme, can remove the methyl group in the $\mathrm{O} 6-\mathrm{MeG}$, which repairs the cytotoxic lesions produced by TMZ. Autophagy can recycle and degrade organelles, cellular proteins, and other cellular components to maintain survival and homeostasis. Autophagy induction is regarded as a mechanism of chemoresistance. Hence, the major mechanism of TMZ resistance is overexpression of MGMT.

The $M G M T$ gene comprise five exons and four introns (13), and is located on chromosome 10q26 encoding a protein of 207 amino acids. MGMT restores normal DNA by transferring the alkyl groups from the O6position of guanine to its own active center Cys145 residue. Consequently, MGMT can resist the methylation damage caused by TMZ. Sato et al. observed a significant interaction between TMZ treatment and MGMT protein expression, with the protein expression of MGMT forecasting a significant reduction in OS (14). Additionally, Nagane et al. evaluated the safety and efficacy of the standard 5-day TMZ regimen in GBM patients, and the results showed that, compared to those with high expression, GBM patients with low protein expression of MGMT had an obviously improved OS and progression-free survival (PFS) (15). MGMT is expressed in a variety of normal cells and tumor cells, and its distribution in different tissues also varies. Related studies have shown that MGMT is highly expressed in normal liver tissues and that the expression level of MGMT in liver cancer is also significantly higher than in other tumors, which may be the cause of resistance of HCC cells to multiple chemotherapy drugs (16). Some studies have shown that MGMT promoter methylation is related to MGMT gene expression and can directly inhibit MGMT gene transcription. Esteller et al. showed that one of the useful predictors of tumor responsiveness to alkylating agent is the methylation of the MGMT promoter in gliomas (17). Meanwhile Hegi et al. reported that TMZ is more effective in treating glioblastoma patients with methylated MGMT promoter than patients without methylated MGMT promoter (18). In addition to promoter methylation, transcription factors are also important forms of regulation of MGMT expression. Several studies have found that NF$\kappa \mathrm{B}, \mathrm{Sp} 1$, and $\mathrm{AP}-1$ transcription factors can activate the transcription of the MGMT gene (19-21). Furthermore, Cabrini et al. used silico analysis to demonstrate that AP-2, ER- $\alpha$, and NF-IL6 nuclear transcription factors may be involved in the transcription of the MGMT gene (22). Transcription factors regulating MGMT expression are affected by multiple cell signaling pathways, such as NF$\kappa \mathrm{B}, \mathrm{Wnt} / \beta$-catenin, and MAPK/ERK pathway. Yu et al. confirmed that the NF- $\kappa \mathrm{B}$ signaling pathway can directly regulate the expression of MGMT and that the inhibition of the NF- $\kappa \mathrm{B}$ signaling pathway decreases TMZ-induced chemoresistance (19). Also, Cabrini et al. reported that Wnt/ $\beta$-catenin signaling pathway regulates the expression of the MGMT gene in cancer and that the inhibition of $\mathrm{Wnt} /$ $\beta$-catenin signaling pathway reduces chemoresistance (22).

ERK was the earliest discovered member of the MAPK family and has been extensively studied and associated with the formation of tumors (23). ERK protein kinase is quickly transferred from the cytoplasm into the nucleus after activation, and acts on c-Jun, NF-AT, NF- $\mathrm{BB}$, and other transcription factors through phosphorylated ERK1/2 


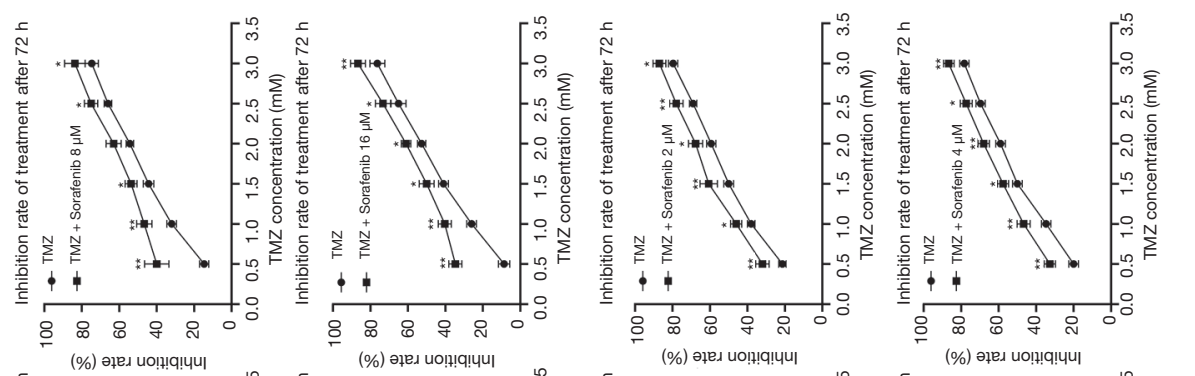

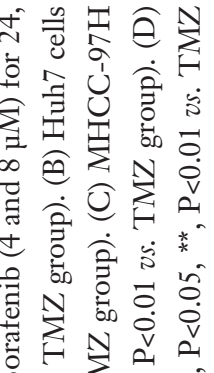
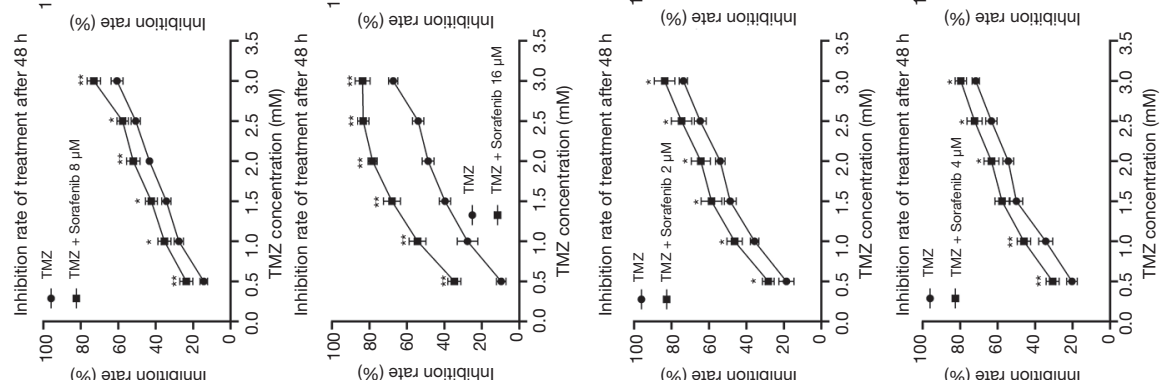

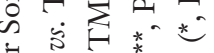

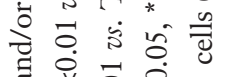

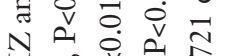

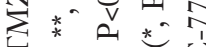

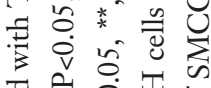

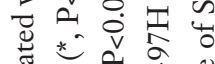
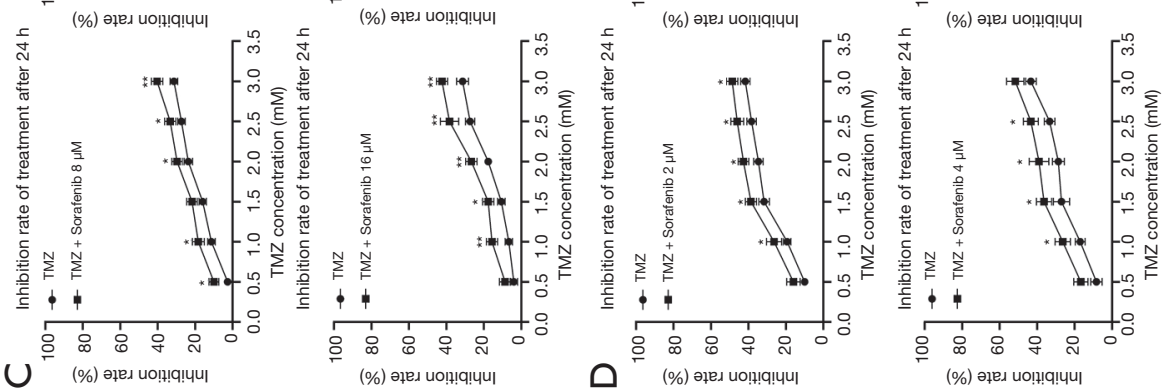

式运它

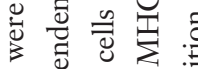

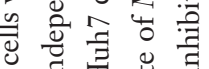

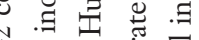

ठ․

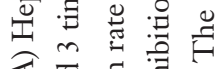

¿

늄

$\exists$.

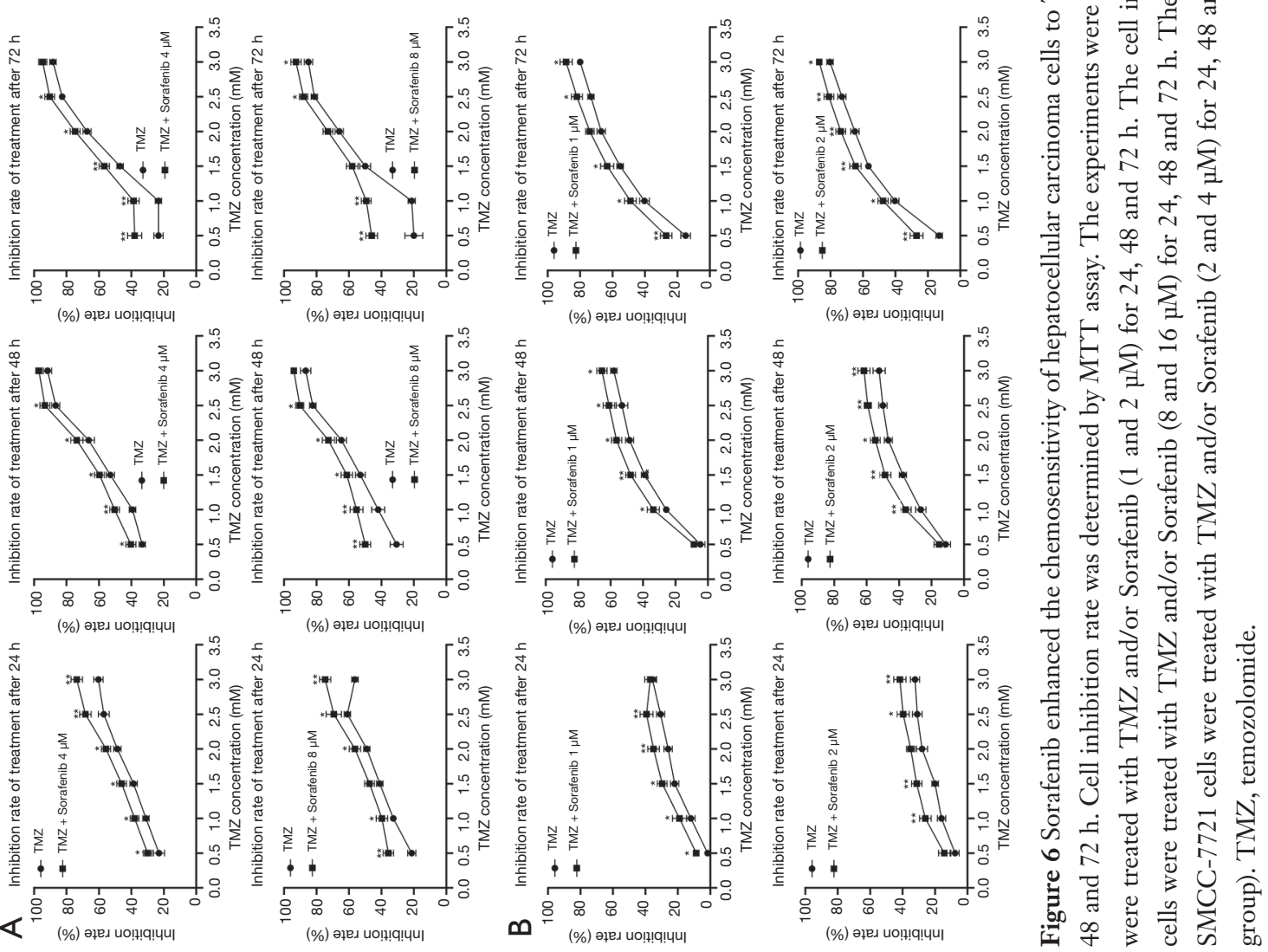


Table 5 The $\mathrm{IC}_{50}$ value of HepG2 cells $(\mathrm{mM})$

\begin{tabular}{lcccr}
\hline Time & TMZ & TMZ + Sorafenib 4 $\mu \mathrm{M}$ & TMZ & TMZ + Sorafenib 8 $\mu \mathrm{M}$ \\
\hline $24 \mathrm{~h}$ & 2.06 & 1.39 & 2.00 & 1.25 \\
$48 \mathrm{~h}$ & 1.05 & 0.84 & 1.10 & 0.68 \\
$72 \mathrm{~h}$ & 1.32 & 0.94 & 1.38 & 0.79 \\
\hline
\end{tabular}

$\mathrm{TMZ}$, temozolomide.

Table 6 The $\mathrm{IC}_{50}$ value of Huh7 cells $(\mathrm{mM})$

\begin{tabular}{lcccc}
\hline Time & TMZ & TMZ + Sorafenib $1 \mu M$ & TMZ & TMZ + Sorafenib 2 $\mu M$ \\
\hline $24 \mathrm{~h}$ & 4.32 & 4.17 & 6.36 & 4.46 \\
$48 \mathrm{~h}$ & 2.21 & 1.77 & 2.48 & 1.77 \\
$72 \mathrm{~h}$ & 1.32 & 0.99 & 1.34 & 1.00 \\
\hline
\end{tabular}

$\mathrm{TMZ}$, temozolomide.

Table 7 The $\mathrm{IC}_{50}$ value of MHCC-97H cells (mM)

\begin{tabular}{lcccc}
\hline Time & TMZ & TMZ + Sorafenib 8 $\mu M$ & TMZ & TMZ + Sorafenib 16 $\mu M$ \\
\hline $24 \mathrm{~h}$ & 5.49 & 5.17 & 5.84 & 4.39 \\
$48 \mathrm{~h}$ & 2.37 & 1.68 & 2.02 & 0.83 \\
$72 \mathrm{~h}$ & 1.64 & 0.97 & 1.76 & 1.13 \\
\hline
\end{tabular}

TMZ, temozolomide.

Table 8 The $\mathrm{IC}_{50}$ value of SMCC-7721 cells $(\mathrm{mM})$

\begin{tabular}{lcccc}
\hline Time & TMZ & TMZ + Sorafenib $2 \mu \mathrm{M}$ & TMZ & TMZ + Sorafenib 4 $\mu M$ \\
\hline $24 \mathrm{~h}$ & 3.38 & 2.94 & 4.37 & 3.11 \\
$48 \mathrm{~h}$ & 1.56 & 1.10 & 1.58 & 1.10 \\
$72 \mathrm{~h}$ & 1.38 & 1.01 & 1.43 & 1.01 \\
\hline
\end{tabular}

$\mathrm{TMZ}$, temozolomide.

to exert biological effects. MAPK/ERK signaling pathway can be found in abnormally high expression and a high activity state in many human tumor tissues. The mechanism of the MAPK/ERK signaling pathway involved in tumor development mainly consists of tumor cells proliferation, the inhibition of tumor cell apoptosis, the promotion tumor blood vessel formation, and the inducement of tumor cell invasion and metastasis. ERK1/2, c-Jun N-terminal kinase (JNK), P38 MAPK, and ERK5/macrionin-activated protein kinase pathway are four main signaling pathways in the MAPK family. The basic composition of the MAPK signaling pathway is a three-level kinase model that is conserved from yeast to humans, composed of MAP kinase kinase kinase (MKKK), MAP kinase kinase (MKK), and MAPK.

MAPK is a family of serine/threonine protein kinases which are widely expressed in eukaryotic cells. Sato et al. demonstrated that a combination of the MEK inhibitor SL327 with TMZ treatment could synergistically sensitize resistant GSCs to TMZ (14). Whether inhibition of the MAPK/ERK signaling pathway in HCC can enhance the chemotherapy effect of TMZ is not clear. To explore this problem, we chose thus chose U0126 in the current study. U0126 [1,4-diamino-2,3-dicyano-1,4-bis(2-aminophenylthio) 

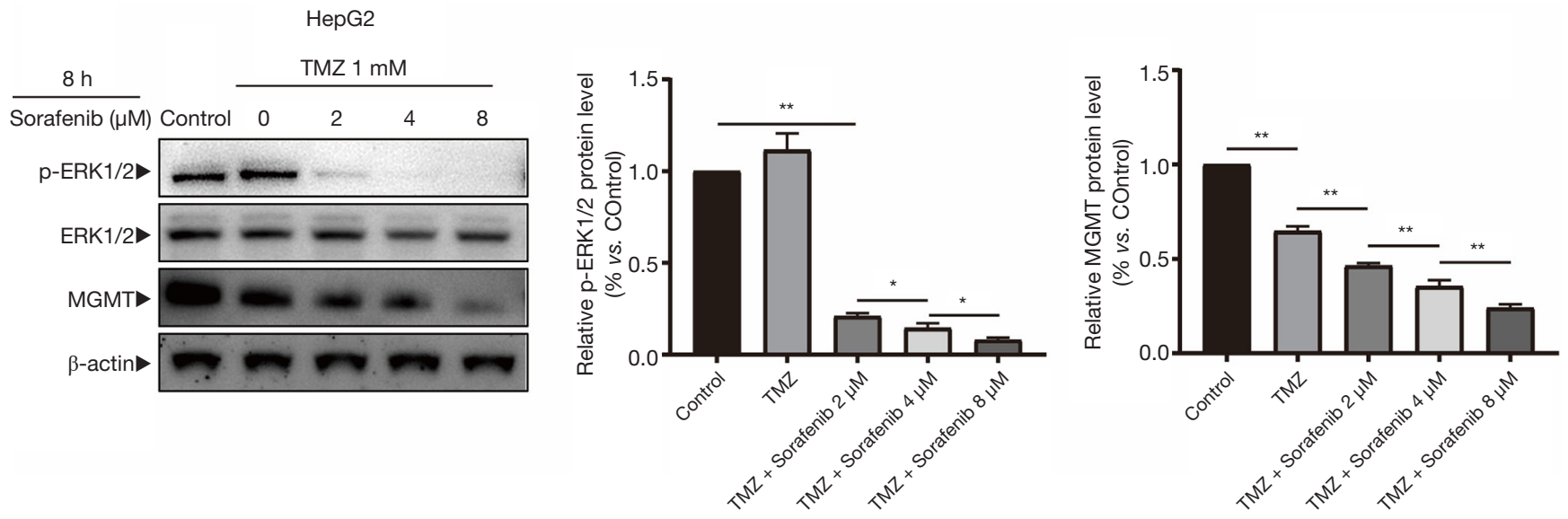

Figure 7 Sorafenib can also decrease MGMT expression in hepatocellular carcinoma cells. Protein expression levels of MGMT, p-ERK1/2 and ERK1/2 were detected when HepG2 cells were treated with TMZ (1 mM) and Sorafenib (2, 4 and $8 \mu M)$ for 8 h by western blot analysis $\left(^{*}, \mathrm{P}<0.05,{ }^{* *}, \mathrm{P}<0.01\right.$ vs. the indicated treatment). TMZ, temozolomide; MGMT, methylguanine-DNA methyltransferase.

butadiene] has been shown to be a highly selective inhibitor of MEK 1 and MEK 2 (24). U0126 was the first of the earliest selective MEK inhibitors to be discovered, and it has been used as an important tool for studying MAPK/ERK signaling pathway, although pharmacokinetics is not suitable for clinical application. In this study, we found that U0126 could increase the sensitivity of HCC cells to TMZ and the DNA damage caused by TMZ. In addition, U0126 could suppress MGMT mRNA and MGMT protein expression in HCC. There were several MAPK/ERK agonists available as positive control in MAPK/ERK pathway research. However, current agonists such as 12-O-Tetradecanoylphorbol-13Acetate (TPA), $\lambda$ phosphatase, Phorbol 12,13-Dibutyrate $(\mathrm{PDBu})$, and growth factors (EGF, HGF, PDGF, et al.) are too less specific to employed in our research. Agonists mentioned above could not only stimulate ERK pathway but also upregulate PKC, Akt or other pathways which could made the application of these agonists unpersuaded. To our knowledge, the most specific ERK pathway activation strategy is mutant constitutive activation MEK1 vector (25), however, since multiple function of ERK pathway was proved, it's obviously that activation of ERK pathway could attenuate TMZ-induced cytotoxicity via promoting proliferation and resisting apoptosis in an MGMT-independent manner. That's the reason why we constructed an MGMT OE vector instead of MEK1 CA vector to confirm ERK inhibition could sensitize HCC cells via MGMT pathway. Our result illustrated that overexpression of MGMT restored U0126induced chemosensitivity to TMZ.

Sorafenib is one of the effective targeted drugs for the treatment of HCC. In the treatment of HCC, Sorafenib works by blocking the downstream conduction of the BAF/ MEK/ERK signaling pathway by inhibiting the serine/ threonine kinase of C-Raf, wild-type B-Raf, and mutant B-RafV600E (26). The expression of phosphorylated ERK in HCC tissue is positively correlated with the therapeutic effect of sorafenib. Sorafenib provides more options for patients with extrahepatic spread and vascular invasion, and, to a certain extent, can also provide long-term survival of patients with advanced HCC. Based on our study which showed that U0126 can enhance the sensitivity of TMZ chemotherapy in HCC, we chose Sorafenib, a widely applicated target drug in HCC which could inhibit multiple kinases including MAPK/ERK, for the same experiment. The results indicated that Sorafenib can also enhance the chemosensitivity of HCC cells to TMZ by inhibiting MGMT expression.

Since our results indicated that ERK pathway could regulate MGMT expression in HCC, a remaining question is what's the mechanism on ERK pathway regulating MGMT expression. According to current literature, ERK pathway modulating downstream transfection factors which may regulate $M G M T$ gene transcription may be a reasonable mechanism. As we know, transcription factors such as c-fos (27), Elk1 (28), SP-1 (29), ETS, slug and snail could be regulated by ERK pathway. Among those, AP-1 (include c-fos and c-jun) (21) and SP-1 (30) was well documented as a regulator of MGMT gene transcription. Hence, it is a reasonable assumption that ERK-AP-1/SP1-MGMT pathway may be a possible mechanism on ERK 
related MGMT expression regulation. Further experiments were required to confirm this hypothesis.

As mentioned above, although, a variety of molecular targeted drugs have been developed for the Ras/Raf/MEK/ ERK signaling pathway and achieved certain therapeutic effects, the overall treatment effect is not ideal. Longterm inhibition of a single signal pathway is prone to drug resistance, which seriously limits the therapeutic effect. At present, targeted drugs for the treatment of HCC have achieved certain efficacy via the blocking of MAPK/ERK signaling pathway to inhibit cell proliferation. Therefore, the treatment of HCC will further focus on the joint application of traditional chemotherapy and targeted drugs. Our studies provide a theoretical basis for the combination of existing ERK inhibitors and alkylating agents in the treatment of HCC.

\section{Conclusions}

In this study, we showed for the first time that MEK inhibitor U0126, in addition to Sorafenib, could sensitize HCC to TMZ. Our findings may be useful in improving the quality of life of liver cancer patients and prolonging their survival time.

\section{Acknowledgements}

Funding: This work was supported by the National Natural Science Foundation of China (no. 81402477 and 81602802), the Natural Science Foundation of Jiangsu Province of China (no. BK20140295), the Jiangsu Government Scholarship for Oversea Studies (no. JS-2018-179), and the clinical trial initiative of the oncology group of the First Affiliated Hospital of Soochow University (no. SLT201913).

\section{Footnote}

Reporting Checklist: The authors have completed the MDAR reporting checklist. Available at http://dx.doi.org/10.21037/ atm-20-5478

Data Sharing Statement: Available at http://dx.doi. org/10.21037/atm-20-5478

Conflicts of Interest: All authors have completed the ICMJE uniform disclosure form (available at http://dx.doi. org/10.21037/atm-20-5478). The authors have no conflicts of interest to declare.
Ethical Statement: The authors are accountable for all aspects of the work in ensuring that questions related to the accuracy or integrity of any part of the work are appropriately investigated and resolved.

Open Access Statement: This is an Open Access article distributed in accordance with the Creative Commons Attribution-NonCommercial-NoDerivs 4.0 International License (CC BY-NC-ND 4.0), which permits the noncommercial replication and distribution of the article with the strict proviso that no changes or edits are made and the original work is properly cited (including links to both the formal publication through the relevant DOI and the license). See: https://creativecommons.org/licenses/by-nc-nd/4.0/.

\section{References}

1. Siegel RL, Miller KD, Jemal A. Cancer statistics, 2019. CA Cancer J Clin 2019;69:7-34.

2. Nenu I, Breaban I, Pascalau S, et al. The future is now: beyond first line systemic therapy in hepatocellular carcinoma. Transl Cancer Res 2019;8:S261-74.

3. Vogel A, Cervantes A, Chau I, et al. Hepatocellular carcinoma: ESMO Clinical Practice Guidelines for diagnosis, treatment and follow-up. Ann Oncol 2019;30:871-3.

4. Nishida N, Kitano M, Sakurai T, et al. Molecular Mechanism and Prediction of Sorafenib Chemoresistance in Human Hepatocellular Carcinoma. Dig Dis 2015;33:771-9.

5. Tong X, Wang Q, Wu D, et al. MEK inhibition by cobimetinib suppresses hepatocellular carcinoma and angiogenesis in vitro and in vivo. Biochem Biophys Res Commun 2020;523:147-52.

6. Wang Y, Zhang X, Gao L, et al. Cortistatin exerts antiproliferation and antimigration effects in vascular smooth muscle cells stimulated by Ang II through suppressing ERK1/2, p38 MAPK, JNK and ERK5 signaling pathways. Ann Transl Med 2019t;7:561.

7. Ito Y, Sasaki Y, Horimoto M, et al. Activation of mitogenactivated protein kinases/extracellular signal-regulated kinases in human hepatocellular carcinoma. Hepatology 1998;27:951-8.

8. Guan J, Chen XP, Zhu H, et al. Involvement of extracellular signal-regulated kinase/mitogen-activated protein kinase pathway in multidrug resistance induced by HBx in hepatoma cell line. World J Gastroenterol 2004;10:3522-7. 
9. Chen S, Wang Y, Ruan W, et al. Reversing multidrug resistance in hepatocellular carcinoma cells by inhibiting extracellular signal-regulated kinase/mitogen-activated protein kinase signaling pathway activity. Oncol Lett 2014;8:2333-9.

10. Jiapaer S, Furuta T, Tanaka S, et al. Potential Strategies Overcoming the Temozolomide Resistance for Glioblastoma. Neurol Med Chir (Tokyo) 2018;58:405-21.

11. Sun QY, Ding LW, Johnson K, et al. SOX7 regulates MAPK/ERK-BIM mediated apoptosis in cancer cells. Oncogene 2019;38:6196-210.

12. Song CQ, Li Y, Mou H, et al. Genome-Wide CRISPR Screen Identifies Regulators of Mitogen-Activated Protein Kinase as Suppressors of Liver Tumors in Mice. Gastroenterology 2017;152:1161-73.e1.

13. Fang Q, Loktionova NA, Moschel RC, et al. Differential inactivation of polymorphic variants of human O6alkylguanine-DNA alkyltransferase. Biochem Pharmacol 2008;75:618-26.

14. Sato A, Sunayama J, Matsuda K, et al. MEK-ERK signaling dictates DNA-repair gene MGMT expression and temozolomide resistance of stem-like glioblastoma cells via the MDM2-p53 axis. Stem Cells 2011;29:1942-51.

15. Nagane M, Kobayashi K, Ohnishi A, et al. Prognostic significance of O6-methylguanine-DNA methyltransferase protein expression in patients with recurrent glioblastoma treated with temozolomide. Jpn J Clin Oncol 2007;37:897-906.

16. Christmann M, Verbeek B, Roos WP, et al. O(6)Methylguanine-DNA methyltransferase (MGMT) in normal tissues and tumors: enzyme activity, promoter methylation and immunohistochemistry. Biochim Biophys Acta 2011;1816:179-90.

17. Esteller M, Garcia-Foncillas J, Andion E, et al. Inactivation of the DNA-repair gene MGMT and the clinical response of gliomas to alkylating agents. $\mathrm{N}$ Engl J Med 2000;343:1350-4.

18. Hegi ME, Diserens AC, Gorlia T, et al. MGMT gene silencing and benefit from temozolomide in glioblastoma. N Engl J Med 2005;352:997-1003.

19. Yu Z, Chen Y, Wang S, et al. Inhibition of NF- $\kappa B$ results in anti-glioma activity and reduces temozolomide-induced chemoresistance by down-regulating MGMT gene expression. Cancer Lett 2018;428:77-89.

20. Aasland D, Reich TR, Tomicic MT, et al. Repair gene $\mathrm{O}(6)$-methylguanine-DNA methyltransferase is controlled by SP1 and up-regulated by glucocorticoids, but not by temozolomide and radiation. J Neurochem
2018;144:139-51.

21. Dhandapani KM, Mahesh VB, Brann DW. Curcumin suppresses growth and chemoresistance of human glioblastoma cells via AP-1 and NFkappaB transcription factors. J Neurochem 2007;102:522-38.

22. Cabrini G, Fabbri E, Lo Nigro C, et al. Regulation of expression of O6-methylguanine-DNA methyltransferase and the treatment of glioblastoma (Review). Int J Oncol 2015;47:417-28.

23. Liang YJ, Yang WX. Kinesins in MAPK cascade: How kinesin motors are involved in the MAPK pathway? Gene 2019;684:1-9.

24. Marampon F, Gravina GL, Di Rocco A, et al. MEK/ ERK inhibitor U0126 increases the radiosensitivity of rhabdomyosarcoma cells in vitro and in vivo by downregulating growth and DNA repair signals. Mol Cancer Ther 2011;10:159-68.

25. Kim BW, Son H. Neural cell adhesion molecule (NCAM) induces neuronal phenotype acquisition in dominant negative MEK1-expressing hippocampal neural progenitor cells. Exp Mol Med 2006;38:732-8.

26. Keating GM. Sorafenib: A Review in Hepatocellular Carcinoma. Target Oncol 2017;12:243-53.

27. Liu C, Ding L, Bai L, et al. Folate receptor alpha is associated with cervical carcinogenesis and regulates cervical cancer cells growth by activating ERK1/2/c-Fos/ c-Jun. Biochem Biophys Res Commun 2017;491:1083-91.

28. Rodriguez-Aguayo C, Bayraktar E, Ivan C, et al. PTGER3 induces ovary tumorigenesis and confers resistance to cisplatin therapy through up-regulation RasMAPK/Erk-ETS1-ELK1/CFTR1 axis. EBioMedicine 2019;40:290-304.

29. Zhao Y, Ma J, Fan Y, et al. TGF- $\beta$ transactivates EGFR and facilitates breast cancer migration and invasion through canonical Smad3 and ERK/Sp1 signaling pathways. Mol Oncol 2018;12:305-21.

30. Yang WB, Chuang JY, Ko CY, Chang WC, Hsu TI. Dehydroepiandrosterone Induces Temozolomide Resistance Through Modulating Phosphorylation and Acetylation of Sp1 in Glioblastoma. Mol Neurobiol 2019;56:2301-13.

(English Language Editor: J. Gray)

Cite this article as: Li Q, Ren B, Gui Q, Zhao J, Wu M, Shen M, Li D, Li D, Chen K, Tao M, Liang R. Blocking MAPK/ERK pathway sensitizes hepatocellular carcinoma cells to temozolomide via downregulating MGMT expression. Ann Transl Med 2020;8(20):1305. doi: 10.21037/atm-20-5478 